\title{
Learning about the past through Situatedness, Embodied Exploration and Digital Augmentation of Cultural Heritage sites
}

\author{
Marie-Monique Schaper, Maria Santos, Laura Malinverni, Juan Zerbini, Narcis Pares \\ Universitat Pompeu Fabra, c. Roc Boronat 138, 08018 Barcelona, Spain \\ \{mariemonique.schaper, maria.santos, laura.malinverni, juan.zerbini, \\ narcis.pares\}@upf.edu \\ Tel.: (+34) 935422631
}

Corresponding author: Marie-Monique Schaper; mariemonique.schaper@upf.edu

\begin{abstract}
:
The design of interactive experiences for archaeological sites entails the consideration of particular characteristics and constraints of the exhibition space. Our aim is to address these challenges by exploring the potential of a recently emerging interaction paradigm called World-as-Support, which is based on projective Augmented Reality (AR). In this study, we present the design process of a virtual heritage experience for a bomb shelter built during the Spanish Civil War and that currently belongs to the History Museum of Barcelona. The goal of this study was twofold. First, we aimed to define the requirements for the design of a first prototype based on the World-as-Support interaction paradigm. Second, we carried out a study with a local school to evaluate the benefits of an educational experience based on this paradigm. Our results indicate benefits to complement the guided visit by using (1) projective AR to explore different layers of the learning experience and (2) by including collaborative activities based on embodied enactments to foster the understanding of historical contents that require emotional engagement and critical thinking.
\end{abstract}

Keywords: World-as-Support, Full-Body Interaction; Learning; Virtual Heritage; Augmented Reality.

\section{Introduction}

Digital technologies are transforming traditional learning experiences in museums. In history education, interactive media can provide meaningful and enriching supports for learners to experience exhibitions and Cultural Heritage $(\mathrm{CH})$ sites. They often entail a meaning-making process that actively engages visitors in multiple acts of recollection, interpretation and communication (Giaccardi and Iversen, 2010). In this regard, they contribute to better understand historical events, preserve cultural values inherited from the past and make them available for present generations.

The role of emerging technologies in the communication of these contents is increasingly at the forefront of the concerns of museums and other heritage custodians. Novel approaches tend to experiment with different augmented modes of visitor experience such as immersion, responsive environments and haptics (Flynn, 2013). In this landscape, learning experiences for spaces such as archeological sites have become an important field for the design of virtual cultural heritage (Ciolfi and McLoughlin, 2012). 
They physically differ from enclosed museum spaces by a number of aspects. First, they allow visitors to approach the archeological remains and artifacts. Furthermore, being situated in a specific space offers visitors a multisensory and immersive experience that cannot be provided by exhibitions in museum buildings that often represent only representations or simulations of the cultural heritage site. The felt-experience on site entails, for instance, visual and auditory stimuli, sensations evoked by physical contact with the historical site, etc.

Although these types of learning spaces allow visitors to become immersed in the site, the provided learning experiences often end up being poorly engaging. On the one hand, these sites are often empty of objects which are probably in museum buildings. Hence, they often display only remains of architectural structures. Moreover, weather can become an important barrier for having fixed information displays and even more audiovisual or interactive material. Finally, notwithstanding weather, archeological sites have often the disadvantage that they cannot be altered by adding physical objects or multimedia installations (Petrelli et al., 2013). Hence, many archeological sites provide personal or audio-guides to direct visitors' attention towards aspects that are not necessarily obvious without further explanation. However, there are still aspects of historical contexts and people's practices in past cultures that are difficult for visitors to imagine (Ciolfi and McLoughlin, 2012). Therefore, there is a growing trend in the exploration of the benefits of ubiquitous computing advanced interfaces (Gena et al., 2016) and context-aware digital augmentation to provide additional information layers within the physical world (Price et al., 2015). In this context, relevant contributions can be found in Augmented Reality (AR) solutions. In particular, projective AR can help to overcome challenges in $\mathrm{CH}$ sites in relation to climatic conditions (e.g. humidity, rain or extreme heat) and heritage conservation policies (e.g. restrictions of modifications for the physical space) because they do not require permanent installation of the hardware on site. Furthermore, they allow visitors to explore site-specific $\mathrm{CH}$ locations in meaningful ways and construct meaning around historical contexts. Building on these benefits, we are exploring the potential of a recently defined interaction paradigm named the World-as-Support (WaS) (Malinverni et al., 2017). This paradigm provides augmentation by projecting the digital content onto the physical world surrounding the user via a handheld device. The portable system, based on a mobile device with computer vision capabilities and a pico-projector, potentially recognizes the surrounding physical world dynamically (i.e. topography, objects, users, gesture and motion) and projects the context-aware digital information directly onto it. In this paradigm, the world becomes not only a physical support for the projected content, but also, and very importantly, it is a support for meaning making due to its intrinsic and situated value and meaning.

Nevertheless, the benefits of this new paradigm need to be carefully evaluated. Research in educational technologies has shown that the affordances of a specific medium can affect learning (Nathan and Robinson, 2001). Furthermore, when designing educational experiences for children, technological solutions and content need to be aligned with the specific capabilities and interest of each target group. Therefore, the main purpose of this study is to design an educational experience based on the WaS paradigm for primary school students in a $\mathrm{CH}$ context and to evaluate its benefits for insitu learning. We present the design process of a first prototype based on this paradigm 
in the context of a bomb shelter built by civilians during the Spanish Civil War. The cultural heritage site called Refugi 307, is currently part of the History Museum of Barcelona.

This paper is structured as follows. In Section 2, we provide an overview of current tendencies for advanced interfaces for archaeological sites and children's educational experiences of heritage. Building on this background, we contextualize our technological approach and highlight the specific features of the WaS interaction paradigm. We also briefly introduce the limitations of designing educational experiences in this research field. In Section 3, we present a case study in which we (1) define the requirements for a digital heritage experience for the bomb shelter, (2) employ and evaluate the educational experience of the WaS interaction paradigm in a first design iteration. In Section 4, we close by discussing how this paradigm can establish meaningful relationships between the learning experience and this particular type of $\mathrm{CH}$ site.

\section{Related Work}

\subsection{Advanced Interfaces for Cultural Heritage}

Despite the different content displayed, enclosed museum exhibitions often tend to follow general design principles (Hornecker et al., 2014) and thus allow a wide range of advanced interfaces and interaction techniques. Recent studies focus particularly on how visitors' learning experience can be supported during the visit in the museum by interacting with large-scale environments (Flynn, 2013; Kenderdine et al., 2014; Kourakis et al., 2012; Pietroni and Adami, 2014; Price et al., 2015), mobile technologies such as tablets and smartphones (Lanir et al., 2016; Rennick-Egglestone et al., 2013), mobile eye tracking technologies (Mokatren et al., 2016), or smart tangible objects (Marshall et al., 2016). In contrast, in the context of designing for outdoor heritage sites, museum experts often have to consider very specific requirements and constraints (Hornecker et al., 2014), e.g. specific spatial configurations of the heritage site, the effect of weather conditions on the use of certain technologies, heritage conservation policies, socialcultural aspects on-site, etc. These constraints shape the ways in which technology is designed for and employed in these spaces.

These challenges have been addressed by exploring the potential of different types of digital augmentations and interaction techniques. Digital auditory, visual and haptic augmentations create distinct opportunities for layering the experience and displaying stimuli around the learner's physical surroundings. In this regard, recent studies have shown how advances in technological innovations of portable devices can provide the potential to change how learners engage with the physical environment (Hornecker et al., 2014; Sakr et al., 2016) and enhance the learning experience of the user (RennickEgglestone et al., 2013). For instance, Hornecker et al. (2014) proposed using smart objects coupled with auditory, haptic and visual feedback to augment learning experiences on historical cemeteries. This approach engaged visitors through a multisensory experience and provided the possibility to integrate museum objects in guided tours of outdoor heritage sites. Other approaches suggest the implementation of participative strategies guided through auditory augmentation. For instance, in the project Reminisce, Ciolfi and McLoughin (2012) proposed to overlay the visit in a "living museum" using digital auditory memories narrated by fictional characters that were associated with the site. A mobile application system allowed visitors to reproduce and 
collect these stories that were represented by QR-markers. Furthermore, visitors were encouraged to record own reflections and to share them on a web platform that could be accessed online and in a specific building on-site. These approaches present potential and meaningful ways to engage visitors with the learning contents. However, in historical contexts, visitors still need to imagine missing artifacts, people living during that period, or related events. If the visitors have limited experience and knowledge about the historical context, it may be particularly difficult for them to imagine some of these contents and situations (Schaper et al., 2017).

Addressing these needs, new approaches explore the potential of AR technologies that can provide concrete visual clues and representations of contents about past events to support visitors' imagination. Frequently, these approaches are based on the Windowon-the-World (WoW) interaction paradigm, a well-known ARMR (Augmented Reality Mixed Reality) approach that blends physical and virtual worlds on a single display. Technically, the WoW paradigm is based on using video displays to merge computergenerated images with a user's view of the physical environment (Milgram and Kishino, 1994). For mobile technologies, this paradigm can be achieved by overlaying the virtual world on top of a live video stream captured from the surrounding physical environment. This "see-through effect" allows users to view and interact with virtual objects in a similar way to the physical interaction with real objects (Müller et al., 2016). In the context of cultural heritage sites, several scholars have taken advantage of the potential of this paradigm. For instance, Pacheco et al. (2015) proposed a location-based AR application for the Bergen-Belsen memorial site, which overlays virtual buildings on the views of the physical space where the now lost buildings were originally located in 1945. Nonetheless, recent studies have pointed towards the risk of these technologies drawing user attention away from the physical space onto a framed window which tends to isolate and provide an individual experience (Betsworth et al., 2014). In this situation, WoW systems seem to miss the fact that the users are located in situ since these live the experience mainly through the screen of the smartphone or tablet device. Hence, the employed technology can become a distraction or even the main focus of the visit, instead of the physical site. This has been formally observed by Müller et al. (2016) who analyzed user behavior in a collaborative task with a tablet-based AR application. They highlight that almost no participants paid attention to the physical environment during the experience.

To tackle these issues, during the last decade, scholars have made different attempts of using handheld devices to reveal content directly in the physical space of $\mathrm{CH}$ sites. For the visit of the Nottingham caves, Ghali et al. (2003) implemented an experience in which visitors used flashlights to explore the walls of the cave by triggering voices whenever the light crossed certain physical features. The same scholars also explored the potential of this tracking system to directly manipulate virtual objects via flashlights on visual interfaces (Green et al., 2002). However, this approach still implies a physical installation of the tracking system in the caves. As previously mentioned, this can be a crucial issue when designing for $\mathrm{CH}$ sites because they often cannot be altered or permanently installed technology may not endure climatic conditions on site. To address this, Betsworth et al. (2014) presented a mobile prototype to research the benefits of performative, place-based projection. The system was based on detecting QR codes situated at key locations within the physical environment which then triggered place- 
based AR projections. The system was implemented for a guided tour in a botanical garden. The outcomes showed that the use of the system actively users involved in the experience and provided them with "an extra dimension" (Betsworth et al., 2014) of the learning content. Furthermore, besides the QR-Codes as markers, the system did not require any additional alteration or technological installations on site.

Despite these first attempts in the research of $\mathrm{HCl}$ and $\mathrm{CH}$, we argue that the learning potential of this approach has still not been fully researched. We have conducted preliminary studies applying the WaS interaction paradigm in an educational context (Malinverni et al., 2017). The results have shown that the paradigm has the potential to enhance student's learning experience in multiple ways. The paradigm is based on projective AR; i.e. augmentation is achieved by projecting the digital content on the physical world surrounding the user via a handheld device. This portable system, based on a mobile device with computer vision capabilities and a pico-projector, dynamically recognizes the surrounding physical world (i.e. topography, objects, users, gesture and motion) and projects the context-aware digital information directly onto it. This allows interaction designers to take advantage of the benefits of Reality-Based Interaction, such as environment awareness and social awareness (Jacob et al., 2008). Moreover, as users act within the physical world to interact with digital content (Dourish, 2001) it affords the potential of bodily and tangible interaction such as tangible manipulation, spatial interaction, and embodied facilitation (Hornecker and Buur, 2006). In previous studies, we compared the affordances of the WaS and the WoW paradigms in the context of a storytelling application for primary school students. Our results provided strong clues of the potential of the WaS paradigm to support environment awareness, context awareness and shape the social relationships between users (Malinverni et al., 2017).

In the context of interaction design for archaeological sites, we argue that using the WaS paradigm can provide the following potentials:

(1) It addresses the risks of having students focus only on the on-screen experience. Consequently, it provides a balanced addition of historical contents without disrupting the immersive experience of being on site.

(2) It provides opportunities for multi-user engagement and collaborative tasks that can help reveal new layers of the experience and promote different viewpoints upon historical events. Thus, this shared action of meaning construction allows students to obtain a holistic understanding of the historical context.

(3) Furthermore, this paradigm allows students to interact with digital content directly on the physical world. This provides an interesting potential related to the user's body and its relation with the world and objects, such as: spatial interaction, tangible interaction and embodied interaction. Thus, the embodiment of actions of people from past civilizations, offer students emotional anchors and strengthen their empathy.

However, the WaS paradigm is still unexplored in the field of learning experience for heritage education with school children. Its benefits and affordances for educational strategies at $\mathrm{CH}$ sites need to be carefully examined. 


\subsection{Designing Educational Heritage Experiences for children}

Digital technologies can provide relevant support for learners to engage with heritage contents. Over this decade, several learning experiences have been developed for museums and $\mathrm{CH}$ sites addressing different aspects of learning such as fostering students' skills towards the understanding of past events (Sakr et al., 2016; Tarumi H.a Yamada, 2008), culture and identity (Smith et al., 2011), perspective-taking (Kourakis et al., 2012), critical thinking (Rowan et al., 2016), collaboration (Carreras and Pares, 2006; Kynigos et al., 2010), among others. To achieve these educational goals, scholars have investigated the benefits of a wide range of interaction modalities with young visitors. For instance, Sakr et al. (2016) investigated how emotional engagement had an impact on children's learning experience about events related to World War II. Students were engaged with a set of location-based tasks while using a digital environment designed for the iPad. Stanton et al. (2003) researched the benefits of adult-child interaction to facilitate children to discover, reason and reflect upon historical places and events. The virtual heritage experience We Hunters (Kourakis et al., 2012) invited children to experience and learn about hunting strategies which were illustrated in a cave painting by using Full-Body actions. This helped them to "embody" certain enactments of people from those ancient cultures and to better contextualize underlying socio-cultural meanings in relation to the museum exhibition.

Despite the long-standing tradition of co-design practices (Muller and Druin, 2003), research in educational heritage experiences for children is often based on a DesignerDriven approach (Malinverni and Pares, 2014). As a consequence, recent studies claim that particularly children are often not attracted by standard communication styles of museums (Dindler et al., 2010). To address these shortcomings, current research increasingly involves stakeholders such as experts, teachers and children in the design process. For instance, the project Digital Natives exhibition (Smith et al., 2011) focused on contemporary heritage practices of young people. Therefore, six teenagers were involved as co-creators and protagonists of an exhibition based on five interactive experiences. They allowed visitors to experience teenagers' everyday cultures, identities and communication practices in new ways and stimulated an intergenerational dialogue about heritage content of the digital era.

We argue that there are still important limitations in the involvement of children and the employment of adequate design methods in this research field. Thus, in this paper, we present a design process of an education heritage experience aimed to explore design strategies that allow researching the different needs and viewpoints of children and adult stakeholders.

\section{The study: Design of a Virtual Heritage experience for the bomb shelter Refugi 307}

Our study was carried out in the context of a cultural heritage location; namely the Refugi 307. The site is one of the 1,402 bomb shelters that were built by civilians during the Spanish Civil War in Barcelona aimed at protecting the population. This shelter is nowadays part of the History Museum of the city which provides guided visits through 
the site. The goal of the project was to explore new possibilities to complement the current guided visit with an educational virtual heritage experience.

Therefore, we first conducted a contextual inquiry (Wixon et al., 1990) and informant design study (Scaife and Rogers, 1999) with (10 to 12 years old) students and teachers of a local primary school and a team of experts of the history museum. During the informant design approach, the researchers involved the stakeholders at stages in which they consider their input as appropriate and critical (Walsh et al., 2013). The aim was to analyze the requirements for the design of the educational experience based on the WaS interaction paradigm and include different needs and viewpoints of the involved stakeholders. Subsequently, we implemented a set of educational activities in a first prototype. We then evaluated students' educational experience of the prototype during a guided visit of the shelter. We will now outline the applied methodology in each design stage.

\subsection{Gathering Requirements}

\subsubsection{Procedure}

\section{Consulting Experts}

To analyze the educational goals of the project, semi-structured interviews were conducted with four teachers and three guides in the installations of the shelter after a visit (in addition, one teacher sent us her answers by e-mail). The questions focused on how they perceived children's reactions during the guided visit, which interests students had in the historical context of the Spanish Civi War, and how the visit could be improved. At the time of the study, the general visit with school classes was structured in a session of 90 minutes. The group was accompanied by explanations of a guide who stimulated students' participation and reflections through questions about the historical context. At the end of the visit, a short video was projected in the shelter that showed general scenes of civilians in Barcelona during the Spanish Civil War.

Furthermore, before the study, three project meetings were carried out in the premises of the museum in which three researchers, a curator, a museum educator and a visit guide discussed topics around the goals of the study, the proposed technological approach and the procedure of the activities. The team from the museum was specialized in $\mathrm{CH}$ and educational museum activities. Our design team contributed with an interdisciplinary background in design and engineering.

\section{Involving Children}

An important requirement for our project was to involve the viewpoints of all stakeholders. Specifically, we aimed to give students, the main users of the educational experience, a voice in the design process. Hence, we observed their behaviors in-situ during the visit. Furthermore, to obtain additional information about their understanding and interests, we explored different strategies of on site and classroom activities that could elicit contributions of the children.

\section{Session 1}

The first session lasted for 120 minutes (90 minutes guided visit in the shelter and 30 minutes workshop activities). In total 40 children (girls $=18$, boys $=22$; mean age $=10.78$ 
years) of two school classes participated in this design stage. We accompanied two guided visits with 20 students each. The students in each group were peers from the same school class. Both visits followed the same procedure. The children were first introduced to the historical context using posters placed at the entrance area just outside the shelter. They depicted historical photo material and written descriptions (figure 1, left). The content was then contextualized within the shelter. The guide drew children's attention towards specific physical features and illustrated content through anecdotes and historical facts about the Spanish Civil War and contemporary events (figure 1, right). Two researchers accompanied each guided visit. The two sessions were video recorded. Furthermore, the researchers took notes about (1) students' interactions within the space (movements, gestures, body posture), (2) facial and verbal expressions and (3) social interactions between each other, teachers and the guide at the different locations in the shelter.

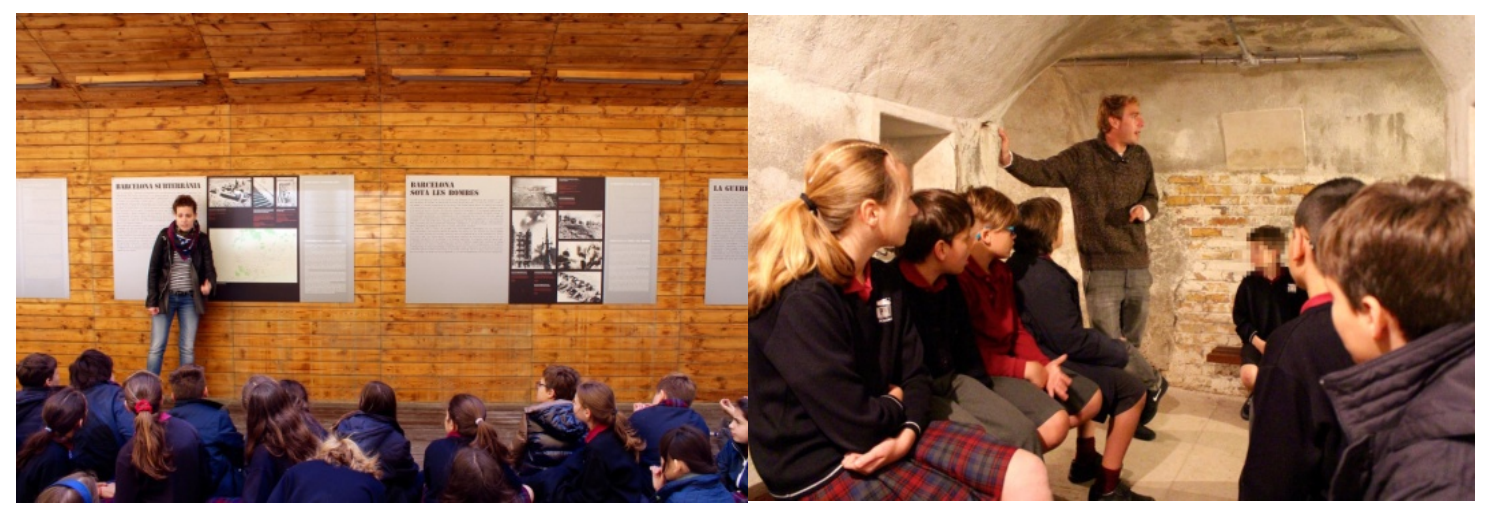

Figure 1. The procedure of the guided visit was divided into two parts: (1) an introduction outside the shelter, (2) a visit inside the shelter to contextualize the learning contents.

After the visit of the shelter, we divided the children into groups of 3-4 members and instructed them in an activity based on the KidReporter technique (Bekker et al., 2003). Each group was asked to record a 2-minute video interview about the place in the shelter that they found most interesting. To do that, we handed out a map of the shelter to each group and gave them 10 minutes to choose one place of interest and brainstorm how they would perform their recorded interview. The aim of this activity was to give the students an opportunity to revisit locations of their interest that they had previously seen during the guided visit. We assumed that being in-situ would help them to better reflect upon the historical context and connect with civilians' feelings during the Spanish Civil War.

After this activity, we handed out a questionnaire to each child aimed at assessing their interests, their understanding of the site, and preferences in accordance with the learning topic and the physical space. The questionnaires were based on open-ended questions that children were asked to complement such as "What I dis/liked about the visit the most was ... because...", "The place I found most interesting was ... because...", "I was disappointed by..."

\section{Session 2}

The second session was held in the school a few days later and lasted for 180 minutes. The children were again divided into the same groups. Using the maps of the shelter, 
they were asked to indicate and explain the places that they remembered and that had caught their attention the most (figure 2 , left). The children wrote their comments on postit notes and placed them on the map. We interviewed each group individually during the activity. The purpose of this activity was to provide children with a link between the content of the visit and subsequent activities during the workshop session. We assumed that the activity would draw children's attention particularly towards the physical features of the shelter and its relation to the historical context. This was important for the design of the educational experience based on WaS because one of its main features consisted in the possibility to interact with digital content onto the physical world.

After that, each child received a different storyboard template (figure 2, right) that was already filled out with a first scene. Each template depicted a different drawing made by children during the Spanish Civil War. They were encouraged to think of a narrative related to the presented drawing. The aim of this activity was to evaluate children's interests and personal values in relation to the historical context, and how they contextualized it in their present time.

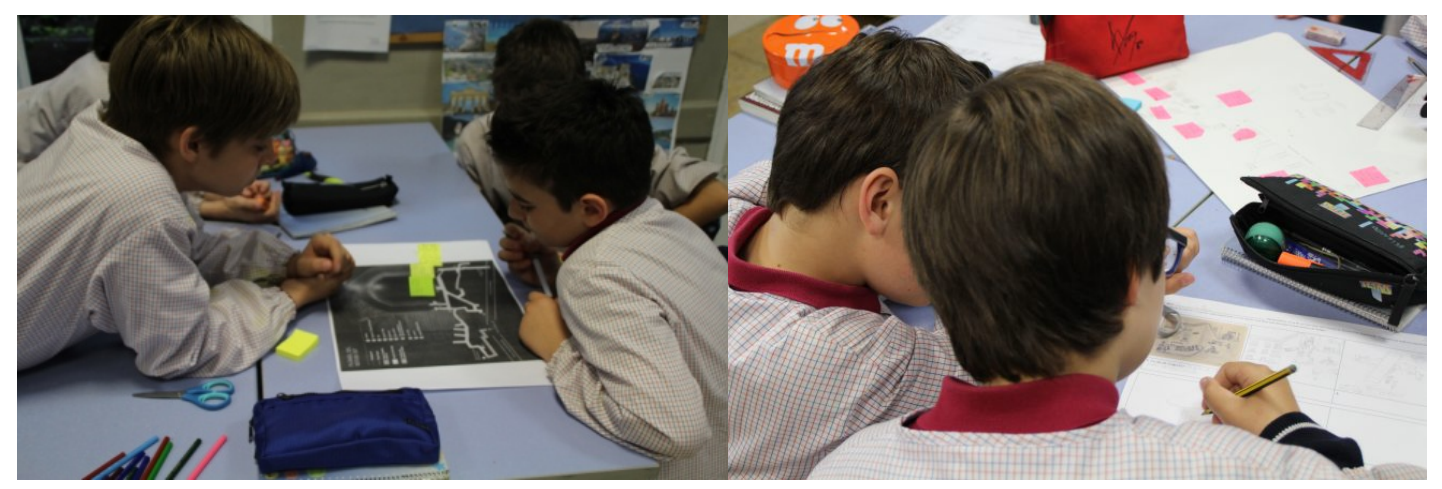

Figure 2. The children received a copy of a pre-defined map of the shelter and used post-it notes to indicate their interests. They received then a storyboard template and were invited to think of a narrative related to the presented drawing.

Subsequently, the children were instructed to re-design the guided visit according to their own interests and preferences. To introduce this activity we presented them, for the first time, a concept of the WaS system based on a Philips PicoPix PPX3414 pico-projector. Subsequently, we asked children to help us in redesigning the educational experience of the shelter guided visit. The children were then asked to produce low-tech prototypes using "projection flashlights"; i.e. drawings on transparent plastic, placed at one end of a paper roll with a flashlight inside to simulate the projection capabilities of a handheld device based on a pico-projector (figure 3). During all workshop activities, we recorded short video interviews with each group while they were working on their proposals. Finally, each group gave a 5-minute presentation to explain and enact their ideas with the low-tech prototype. 


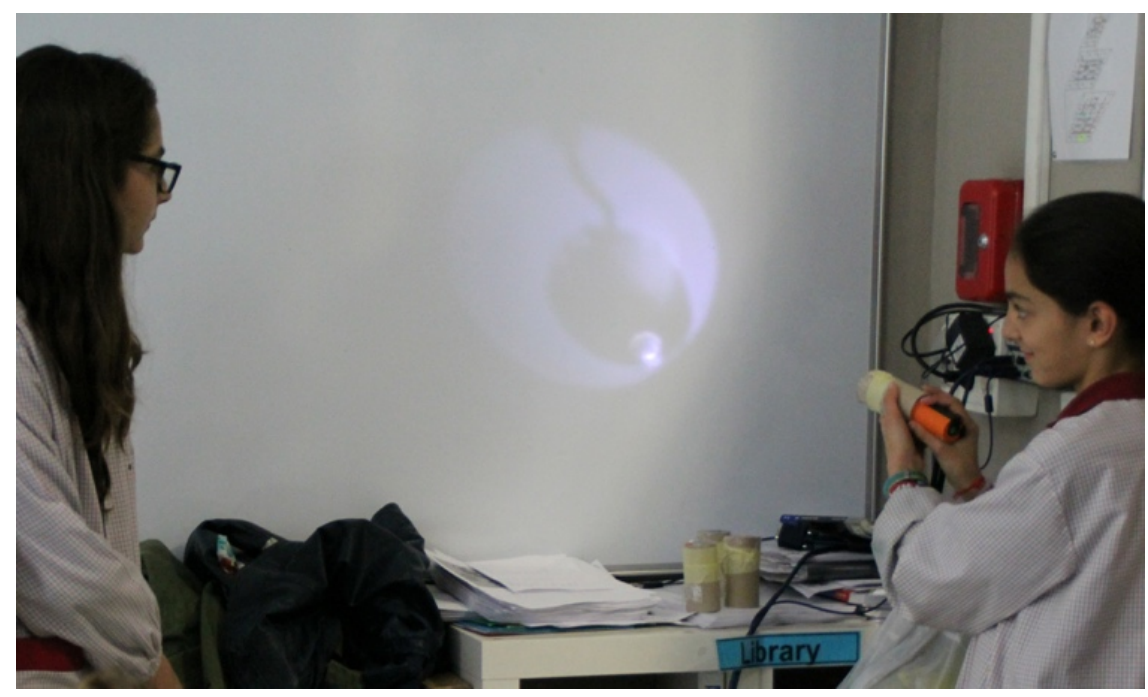

Figure 3. The children presented their ideas for the improvements for the guided visit using a low-tech prototype.

\subsubsection{Analysis of Requirements}

The aim of this design stage was to conduct an analysis of the current learning experience on-site and to compare them with the educational goals defined by experts. This comparison allowed us identifying aspects of the existing guided visit that could be complemented using the WaS paradigm. To analyze children's contributions, we applied a multimodal analysis approach (Kress, 2010; Malinverni et al., 2016; Sakr et al., 2016; Van Mechelen et al., 2016) to collect, analyze and interpret the multiple resources that children employed during the activities (e.g. body postures, spatial interaction, facial expressions, gaze, verbal expressions, drawings, etc.). Multimodality is an interdisciplinary approach, derived from socio-semiotics, that aims to understand how people communicate and represent meaning in different forms (Price and Jewitt, 2013). In our study, the goal of the evaluation was to better understand stakeholders' meaningmaking of the educational experience in the shelter by including their contributions from a perspective that went beyond the limits of verbal language. Particularly, when working with children the multimodal approach has shown to effectively inform the design process (Malinverni et al., 2016; Van Mechelen et al., 2016). Due to children's limited linguistic competence, it is often difficult for them to express their thoughts and explain ideas adequately. By focusing in the evaluation on different semiotic resources that are employed to construct meaning, we argue that this approach can provide us insights into how children express their worldviews in relation to the educational context through their body and person-environment interaction. Hence, this approach could help us to understand how in situ learning during the guided visit influenced children's meaningmaking processes.

Therefore, the material from video- and audio recordings, annotations and children's contributions (drawings, post-it notes, storyboards, maps, etc.) was transcribed in a descriptive format and analyzed using the software NVivo 11. We used a coding scheme derived from the five dimensions of experience in physical space proposed by Lentini and Decortis's (2010), namely Geometrical and Geographical experience, Sensorial 
experience, Cultural experience, Personal experience and Relational experience. According to the authors, these analytic lenses combined aspects of both computing research and environmental psychology by considering the complexity of relationships between humans and the physical space. This framework is meant to inform the design of technologies that support meaningful interactions with and in the physical space. We decided to build our analysis on this coding scheme because it focused on user situatedness. In our study, we claim that the WaS interaction paradigm unfolds its full potential when it is employed in site-specific contexts. Furthermore, we argued that the separation of the in-situ learning experience into different layers could help us identifying deficiencies in the current experience and specific requirements for our technologyenhanced learning approach. However, the original framework was not specifically aimed to analyze learning experiences. Thus, for our purpose, we extended and regrouped the original lenses (Table 1). Finally, we defined the following four-layers model for our analysis:

Physical Space Layer: Analysis of the (1) specific physical features of the shelter and (2) possible opportunities and restrictions for using technology on-site.

Narrative Space Layer: Analysis of the content of the guided visit in relation to (1) the specific features of the physical space and (2) the learning goals of the educational experts.

Personal Space Layer: Analysis of the interest and in-situ experience at an individual level that are promoted by (1) understanding of the historical context, (2) emotional engagement and (3) sensorial contact with the physical space.

Collective Space Layer. Analysis of (1) social interactions during the guided visit that offer opportunities for collective learning activities; (2) the understanding of socio-cultural values among children and experts.

Table 1: Overview of similarities and differences between Lentini and Decortis's and our approach of dimensions for experiences in physical space

\begin{tabular}{|c|c|c|c|}
\hline \multicolumn{2}{|c|}{ Lentini and Decorti's Dimensions } & \multicolumn{2}{|l|}{ Our Approach } \\
\hline $\begin{array}{l}\text { Geometrical } \\
\text { and } \\
\text { Geographical } \\
\text { experience }\end{array}$ & $\begin{array}{l}\text { The apprehension of the } \\
\text { spatial qualities of the } \\
\text { environment, i.e. estimation } \\
\text { of distance, structure, } \\
\text { shape of the setting, and } \\
\text { the spatial disposition of the } \\
\text { different elements } \\
\text { composing the setting. }\end{array}$ & Physical Space & $\begin{array}{l}\text { The specific physical } \\
\text { features of the shelter } \\
\text { and possible } \\
\text { opportunities and } \\
\text { restrictions for using } \\
\text { technology on-site. }\end{array}$ \\
\hline - & - & Narrative Space & $\begin{array}{l}\text { The content of the guided } \\
\text { visit in relation to the } \\
\text { specific features of the } \\
\text { physical space and the } \\
\text { learning goals of the } \\
\text { educational experts. }\end{array}$ \\
\hline
\end{tabular}




\begin{tabular}{|c|c|c|c|}
\hline $\begin{array}{l}\text { Personal } \\
\text { experience }\end{array}$ & $\begin{array}{l}\text { The meaningful } \\
\text { experiences-in-place that } \\
\text { are mainly experienced at } \\
\text { an individual level. These } \\
\text { are the opportunities that } \\
\text { places offer for reflection, } \\
\text { introspection, self-under- } \\
\text { standing and personal } \\
\text { growth. }\end{array}$ & \multirow[t]{2}{*}{$\begin{array}{l}\text { Personal } \\
\text { experience }\end{array}$} & \multirow[t]{2}{*}{$\begin{array}{l}\text { The interest and in-situ } \\
\text { experience at an } \\
\text { individual level that are } \\
\text { promoted by } \\
\text { understanding of the } \\
\text { historical context, } \\
\text { emotional engagement } \\
\text { and sensorial contact } \\
\text { with the physical space. }\end{array}$} \\
\hline $\begin{array}{l}\text { Sensorial } \\
\text { experience }\end{array}$ & $\begin{array}{l}\text { The apprehension of the } \\
\text { sensorial qualities of the } \\
\text { environment: the colours, } \\
\text { the smells, the material, } \\
\text { and the textures. }\end{array}$ & & \\
\hline $\begin{array}{l}\text { Cultural } \\
\text { experience }\end{array}$ & $\begin{array}{l}\text { The apprehension of the } \\
\text { behavioural } \\
\text { appropriateness, of the } \\
\text { cultural expectations and } \\
\text { understandings of } \\
\text { behaviours, and corollary of } \\
\text { the activities that are } \\
\text { expected (and accepted) to } \\
\text { occur in a particular setting. }\end{array}$ & \multirow[t]{2}{*}{ Collective Space } & \multirow[t]{2}{*}{$\begin{array}{l}\text { Social interactions during } \\
\text { the guided visit that offer } \\
\text { opportunities for } \\
\text { collective learning } \\
\text { activities; the } \\
\text { understanding of socio- } \\
\text { cultural values among } \\
\text { children and experts. }\end{array}$} \\
\hline $\begin{array}{l}\text { Relational } \\
\text { experience }\end{array}$ & $\begin{array}{l}\text { The opportunities for } \\
\text { interpersonal relationships } \\
\text { and interactions that } \\
\text { happen in places, } \\
\text { contributing to our } \\
\text { development as individuals } \\
\text { and as members of a } \\
\text { community. }\end{array}$ & & \\
\hline
\end{tabular}

The analysis was performed by two researchers. After a process of individual coding, a common agreement was reached through a number of meetings and discussions about the results.

\subsubsection{Results}

\section{Physical Space Layer}

The shelter was composed of approximately a 200 meter-long twisting tunnel, with a height of 2.10 meters and width between 1.5 and 2 meters (figure 4, left). The narrow space limited visitors' movements. For instance, only one group of maximum 20 children and four adults was allowed in the shelter at a time, and they were asked to walk in pairs due to the spatial constraints. Visitors can get an impression of the living conditions during the Spanish Civil War and some facilities inside such as bathrooms, benches, an infirmary, a children's room, a chimney built into the mountain, etc. The general light 
conditions in the shelter were very poor. Therefore, the guide illuminated certain spaces with a flashlight to direct children's attentions towards specific physical features and traces of objects (e.g. the original lighting system, signs with instructions on behaviour rules, holes to fix stretchers to the wall, etc.) that were once installed inside. The high humidity in the shelter prevented permanent installations of multimedia systems. Security policies for the shelter stipulated that visitors should always be accompanied by a member of the museum. Furthermore, direct physical contact with the walls or artefacts inside the shelter should be avoided to preserve the cultural heritage site.

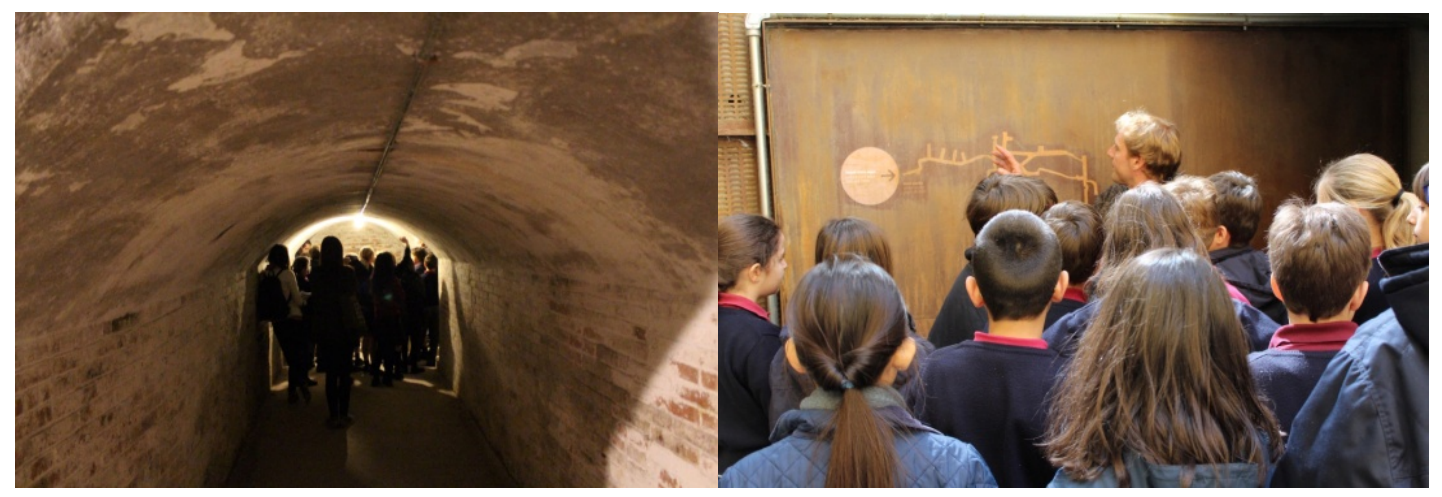

Figure 4. A school class visiting the guided visit of the cultural heritage site Refugi 307.

Due to these restrictions, we discussed the benefits and possible limitations of our technological approach with the museum experts. During the interviews, the museum experts expressed the need to maintain the sensation of "simplicity and sparseness" of the shelter. The aim was to illustrate its original "living" conditions in similar ways as civilians may have experienced them during the war. One expert explained: "We do not want to fill it with museography because it would lose the feeling of entering an empty place that (originally) did not provide anything." They saw potentials in the pervasiveness of the WaS interaction paradigm and the possibility to selectively augment the physical space without altering it. "These projections, you describe, should allow projecting in one moment and then everything disappears and the walls remain as they were." On the other hand, one guide pointed towards the risk that using augmented content may not leave sufficient space for children's imagination and own reflections, particularly if too many interactive learning contents are presented during the visit.

\section{Narrative Space Layer}

The analysis of the visit showed that the museum had organized the contents inside the shelter in a chronological order and in accordance with the spatial configuration (figure 4 , right) of the cultural heritage site. The construction of the shelter was started from three different entrances at a time and meant to be connected with each other. However, only the tunnel parts to the eastern and central entrances were finalized while the western entrance remained isolated. During the post-civil war period, the western part of the shelter was extended and the entrance finally connected to the rest of the shelter. Due to the different building methods, we can easily recognize these two construction periods. Whereas the older parts had a solid construction based on brick walls and roman arches, the newer part consisted only of simple excavations into the mountain. 
The tour guides used these physical references to distinguish between historical contents during the Spanish Civil War and the time after (post-war period, contemporary topics, etc.). Therefore, the visit began at the eastern entrance and followed a linear narrative finishing at the western entrance. (The part of the tunnel that led to the third entrance was not accessible during the visit.) The guides explained historical events and anecdotes in the context of the Spanish Civil War from the year 1936 to the present time.

\section{Personal Space Layer}

The analysis of this layer involved two main aspects. On the one hand, we investigated experts' educational goals related to the visit. On the other hand, we focused on how the students themselves understood the historical context during the visit, with which topics and locations they got emotionally engaged and which sensorial experiences triggered reflections and interpretations.

\section{A) Experts' educational goals}

The findings from the interviews with educational experts from the museum and school determined that one of the main goals of the interactive experience should be to foster children's competence in understanding the relation between historical events from the Spanish Civil War and similar contemporary conflicts occurring today (e.g. the civil war in Syria). This aim involved strengthening feelings of solidarity and empathy with people who have suffered and/or are still suffering war. To offer children emotional anchors to the learning context, they recommend to link the content of the experience to situations children can relate to their own identity; e.g. family members from previous generations or children in war zones in other countries. Furthermore, the teachers proposed to use (1) audiovisual material such as testimonials, original documents, photos, (2) real objects (e.g. a pickaxe, stretchers, medical supplies, etc.), (3) actors performing specific situations and (4) post-activities to contextualize the content explained during the visit and to support children's interpretations.

\section{B) Students' understanding and interests}

Our analysis of children's behaviors during the guided visit and their contributions during the workshop sessions helped us to obtain an in-depth comprehension about their understanding and interests towards the historical context and in-situ experience. During the visit, the children showed surprise and astonishment when they were told anecdotes about civilians in the shelter which were contrary to their own "protected and comfortable" lives. For instance, the guide explained that some women put their children under the benches so that they could stretch out for sleeping and were protected in case of a collapse of the ceiling. In response to this explanation, some children looked disbelieving under their bench and made comments about how uncomfortable that must have been. Another example is when they expressed disgust about the fact that people were forced to eat parts of food that people usually would throw away (e.g. a soup out of mashed fish bones). Several children pointed out that they would never eat something that they did not like.

We observed that several children tended to enact explanations of the guide to have an embodied understanding of the described contents, e.g. one child slapped her hands on the legs when the guide talked about children sleeping on parents' laps. Other children that were sitting on benches started shaking their bodies when the guide mentioned 
shaking walls from bomb explosions. With the physical space, the children interacted mostly through their eyes searching for more details in relation to the explanations. In certain spaces the children looked for direct contact through touch e.g. in the "infirmary" they knocked against the wall to explore the sound it made because of the hollow space inside. Another example is when the children touched the wall of the mountain while the guide was contrasting pickaxe marks of children and adults. Particularly the darkness and humidity in the shelter had an impact on the children. They responded to the low temperatures by expressing uncomfortable feelings through behaviours such as moving from one foot to the other to keep themselves warm, tightly closing their jackets, blowing hot air into their sweater, etc. Also during the workshop activities, they stated several times that it was very uncomfortable to stay inside for a long period of time and they were glad to be able to leave after the visit. We also observed moments when the children were distracted from the guided visit, e.g. some children started playing with each other or made a bored face. This behaviour tended to occur in situations when they were asked to remain still, e.g. in the introduction outside the shelter and during explanations sitting on the benches.

The analysis of the interviews during the KidReporter activity gave us specific insights about children's interests and understanding of the historical context. Six out of 10 groups chose to perform the interview in the "infirmary". They focused on the fact that the place was located in the middle of the tunnel and thus the safest place in the shelter (which has an entrance door on either end). The children also expressed the importance to have a place where injured people could be treated and their respect for volunteering nurses that had only very limited medical resources available to help them. Three groups performed the interview about the "fire place". They expressed their admiration for the person who had built a chimney and ventilation system into the stone of a mountain. They retold two anecdotes related to the place. First, despite the harsh conditions in the shelter, a family from southern Spain lived in it during the post-war period for ten years. Second, a man in the eighties used the shelter to illegally grow mushrooms on the walls as the main income for his family. Only one group performed the activity in the "children's room" and expressed their sadness about an event in which during a bombing attack the ceiling collapsed and two children were injured.

Results extracted from the open-ended questionnaires revealed further interests of the children. Several children mentioned physical characteristics of the shelter; e.g. the zigzag shape of the entrance aimed at avoiding the dispersion of shrapnel from the bomb explosions to the inner part of the shelter; the rounded finish of the walls around corners to facilitate the transport of injured people on stretchers, etc. Furthermore, other children reported their interest on aspects related to people; e.g. dead bodies, blood of injured people, getting to know a Spanish Civil War survivor, etc.

During the subsequent map activity in class (figure 5), in addition to the previously presented places, all groups reported on at least one other location related to people's basic needs: toilets (9 groups), a water fountain ( 8 groups), and a power generator for the lighting system ( 3 groups). In addition, they explicitly mentioned that they were interested to see the original wall signs on behavior rules (1 group), they asked for images of bombs and shrapnel (1 group) and expressed their curiosity about tunnel segments that were not included in the guided visit (2 groups). 


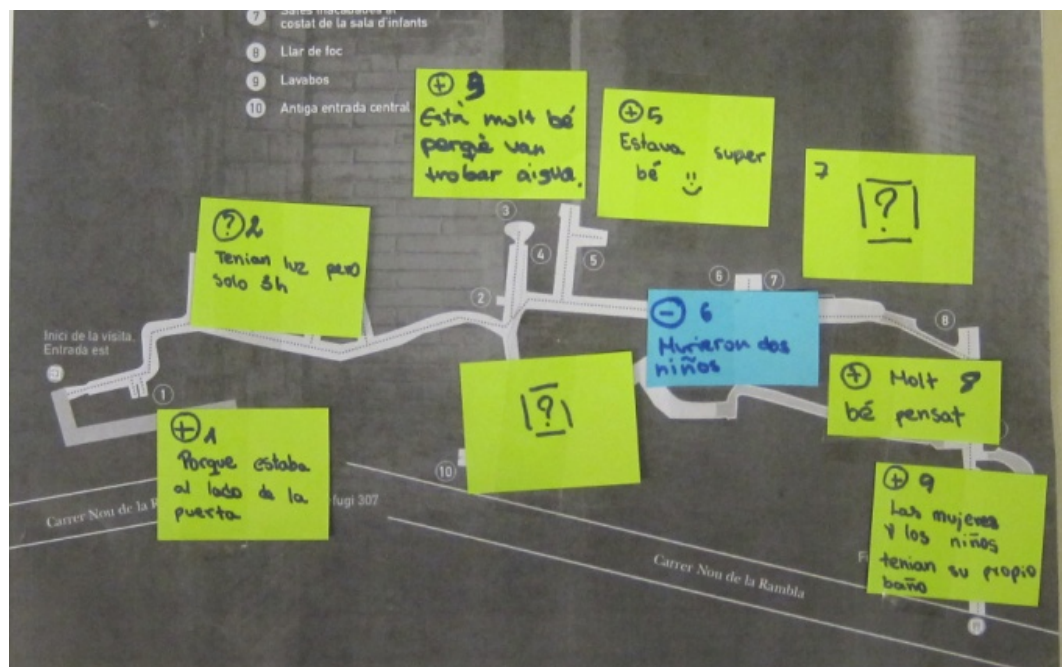

Figure 5. This group was particularly interested in the water fountain and the power generator. The children expressed their sadness about the accident in the children's room. They also expressed curiosity towards parts of the shelter that were not included in the guided visit.

In the redesign activity, the children mainly proposed changes related to making the experience more participative. They proposed several hands-on activities, e.g. (1) a treasure hunt activity with hints to provide a playful experience during the guided visit; (2) an activity where children could dig up the destroyed children's room and discover what was hidden under the stones; (3) to perform a drill activity of the bomb alarm and the experience of entering the shelter.

Children's main misconceptions across the different design activities were related to the expectations of finding weapons in the shelter from people who tried to protect their family against dictator Franco's army (6 out of 40 children). In other words, they did not understand that the shelter represented a "passive" form of defence, in contrast to the "active" defence that involved using weapons. Further analysis showed that particularly boys ( $83 \%$ in total) tended to report a higher amount of misconceptions than girls related to this topic. Moreover, two children expected to find a fully equipped kitchen in the shelter. Another child thought that the room in which children waited during the bombings was used as a playground. These findings indicate that these children had difficulties to imagine the living conditions in the shelter and how civilians probably had felt and behaved in it. Another child thought that men were not allowed to work in the construction of the shelter. The boy was not aware of the fact that during the Spanish Civil War men were forced to go to the frontlines.

To sum up, triangulating different semiotic resources (verbal explanations, body language, manual contributions such as drawings, etc.) that the children expressed during the activities helped us to obtain a holistic picture of their personal perspective of the historical context and in-situ experience during the visit. Our results illustrated that the children showed, in general, a high interest in the historical context and were very engaged in the explanations during the guided visit. Individual fate, civilian's living conditions in the shelter and particularly anecdotes that involved children as protagonists caught their attention. Furthermore, the students were intrigued by the physical characteristics of the shelter and their functions. Children's felt-experience in the physical 
space, enactment of explanations and sensorial contact triggered reflections and meaning-making of the historical context. Nevertheless, the students showed some misconceptions in relation to situations that were unfamiliar to them or involved abstract concepts (such as "passive defense"). Furthermore, they reported needs of visualizing missing and hidden artifacts of the physical space. Finally, they proposed participative activities as improvement for the guided visit. Also during the visit, we observed that the children preferred to move around and explore the space than to sit still and listen to the guide.

\section{Collective Space}

Museum experts highlighted that one main purpose of the guided visit was to transmit children the benefits of collaboration and implications of being part of a community. On the one hand, the shelter itself was a symbol and reflection of social values because people from all ages contributed to its construction aimed to protect themselves, their family and friends against bomb attacks. On the other hand, the museum experts emphasized on the fact that the war had caused a collective trauma and influenced civilians' attitude towards certain political and social movements in society. From a historical perspective, the understanding of these two aspects was important to prevent that mistakes from the past may be repeated.

The storyboard activity helped us to get deeper insights on children's socio-cultural values. The goal of this analysis was to identify differences in the understanding of sociocultural values of the children and educational goals that were defined by the experts. In almost all groups, the children tended to describe their stories from a third person perspective. Four children wrote their stories about the lack of food and how people had to find provisions to survive. One child wrote about men who went to the frontlines. Another child mentioned that people had lost their houses. Two children explained how people were forced to leave their country. However, many of these stories had a "happy end", i.e. as soon as the war ended everything went back to "normal" (figure 6). This result can be interpreted in multiple ways. On the one hand, the results could be primed by common narrative structures of contemporary children's literature (e.g. fairy tales). On the other hand, these findings could point towards children's generally positive attitude to solve problems (Van Mechelen et al., 2016). Finally, these outcomes could indicate that the children were not conscious about long-term effects caused by the war. Comparing these results with the educational goals defined by the expert indicated that the educational experience in the shelter could benefit from activities that promote reflection on social values and help children to understand the concept of "collective trauma" such as the need for collaboration and solidarity. 

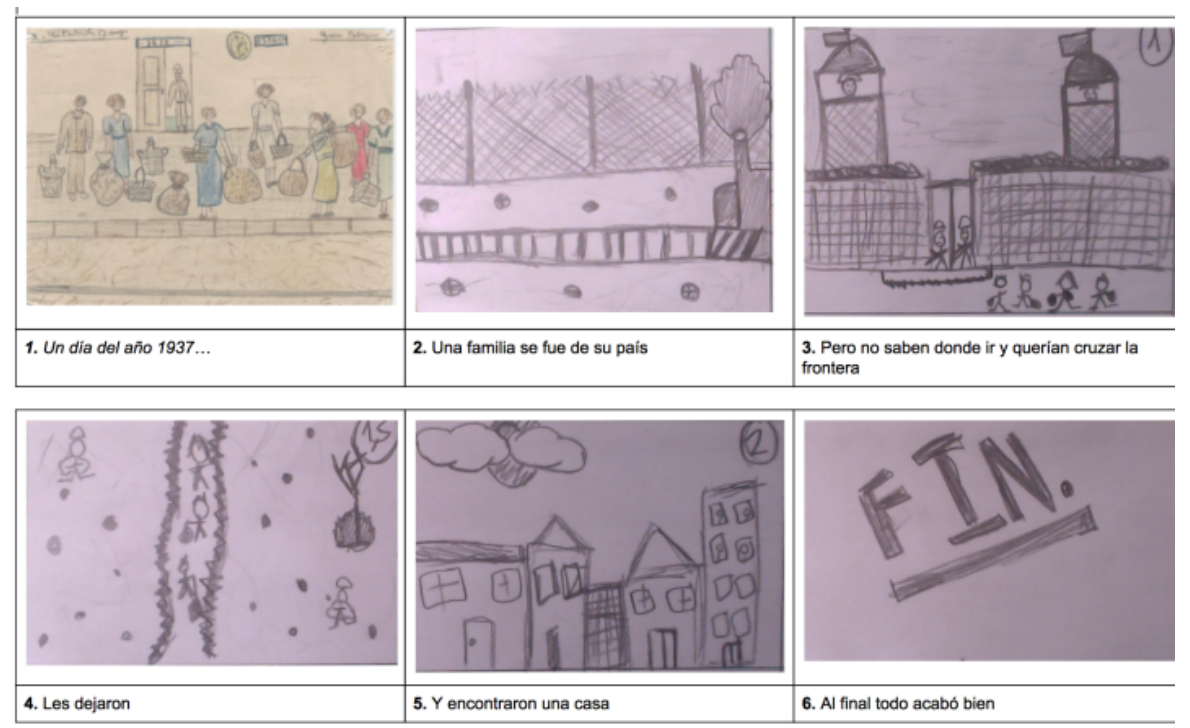

Figure 6: A girl explained in her storyboard how a family had to leave their home and found a "happy" life in another country.

Due to the educational goals defined by the experts, we focused our analysis on children's social interactions and interpretations evoked by the guided visit and aimed to foster the aforementioned concepts and underlying values. Our results depicted that the enactment of content that was explained during the guided visit did not only take place on an individual level but involved interactions among different children at the same time. For instance, in the "infirmary" two girls re-enacted pulling up an injured person from the ground. Furthermore, the children interacted with each other by pointing at certain things in the shelter while the rest of the class followed with their gaze. In other situations, they answered their questions among themselves and discussed aspects of the guided visit that caught their attention. By analysing children's proposals for a redesign of the guided visit we looked for opportunities for interpersonal relationships and interactions that could take place within the space using the WaS paradigm. Interestingly, almost all of children's proposals for the redesign of the guided visit were group activities. They proposed specific participative and hands-on activities such as performing a treasure hunt game, digging up together the collapsed part of the children's room, etc.

\subsubsection{Definition of requirements for a first prototype}

Our approach helped us to define key requirements for the design of a learning experience for this cultural heritage site. Our observations confirmed that the guided visit already had a high educational potential in introducing the historical context and some underlying values to the children. However, we saw several opportunities to complement it through using a virtual heritage experience based on the WaS paradigm (Table 2).

Table 2: Overview of requirements for the design of a first iteration

\begin{tabular}{|l|l|l|}
\hline Layer & $\begin{array}{l}\text { Affordances of current learning } \\
\text { experience and limitations }\end{array}$ & Opportunities for WaS \\
\hline
\end{tabular}




\begin{tabular}{|c|c|c|}
\hline Physical Space & $\begin{array}{l}\text { (1) Spatial constraints restrict movement } \\
\text { possibilities; (2) Poor lighting conditions; ( } 3 \text { ) } \\
\text { Climatic conditions do not allow to } \\
\text { permanently install multimedia systems; (4) } \\
\text { Visitors need always to be accompanied by } \\
\text { a guide; (5) Direct contact with the physical } \\
\text { space should be avoided; (6) Maintenance } \\
\text { of the sensation of "simplicity and } \\
\text { sparseness" }\end{array}$ & $\begin{array}{l}\text { (1) Pervasiveness and selective use; } \\
\text { (2) Projective Augmented Reality } \\
\text { content does not alter the space and } \\
\text { avoids direct contact with it; ( } 3 \text { ) } \\
\text { Allows to highlight and complete } \\
\text { traces of missing objects; (4) Allows } \\
\text { balanced use of augmented content } \\
\text { and verbal explanations to leave } \\
\text { room for children's imagination }\end{array}$ \\
\hline Narrative Space & $\begin{array}{l}\text { (1) Guided visit is organized in a } \\
\text { chronological order and makes reference to } \\
\text { the building process of the shelter and } \\
\text { physical differences in its features }\end{array}$ & $\begin{array}{l}\text { (1) Recognition and exploration of } \\
\text { specific surfaces in the shelter to } \\
\text { contextualize historical events and } \\
\text { anecdotes }\end{array}$ \\
\hline Personal Space & $\begin{array}{l}\text { (1) Aim to strengthen feelings related to } \\
\text { empathy and solidarity; (2) High impact of } \\
\text { felt-experience in the shelter; ( } 3 \text { ) Guided } \\
\text { visit triggers enactments and reflections } \\
\text { upon harsh living conditions in the shelter; } \\
\text { (4) Children are bored in situations when } \\
\text { they just listen and remain still (5) Guided } \\
\text { visit fails transmitting the difference between } \\
\text { active and passive defence (6) Children had } \\
\text { problems to understand difference in cultural } \\
\text { values during the Spanish Civil War and } \\
\text { today (e.g. the role of women and men in } \\
\text { society) }\end{array}$ & $\begin{array}{l}\text { (1) Participative and hands-on } \\
\text { activities that involve the } \\
\text { visualization of rule signs and bomb } \\
\text { impacts; (2) Fostering children's } \\
\text { interest in people and contrasting } \\
\text { changes in cultural values by using } \\
\text { testimonials and material showing } \\
\text { civilians during the war (3) Activities } \\
\text { based on embodiment of actions } \\
\text { from people in the past }\end{array}$ \\
\hline Collective Space & $\begin{array}{l}\text { (1) Aim to transmit benefits of community } \\
\text { values was well understood by the children; } \\
\text { (2) Children showed problems to relate to } \\
\text { the significance of collective trauma (stories } \\
\text { had a happy end) }\end{array}$ & $\begin{array}{l}\text { (1) Participative activities that foster } \\
\text { social interaction and mutual } \\
\text { reflection; (2) Connecting to } \\
\text { contemporary contents such the } \\
\text { problematic of refugees from Syria }\end{array}$ \\
\hline
\end{tabular}

Our findings showed that due to the spatial constraints of the shelter that the guided visit could benefit from the WaS paradigm as follows. Projective AR content allows to draw children's awareness to specific features in the environment and to augment missing information of objects in their original locations (e.g. the signs of behavior rules can be projected on the empty holes on the walls) without altering the physical space. These projections based on surface and object recognition may contextualize contents and facilitate children to imagine objects they have never been in contact with. Furthermore, the WaS allows a flexible employment and, therefore, can selectively be used to complement the guided visit, i.e. only in moments when the guide considers that additional information is required to foster certain understandings and reflections upon the learning topic.

We propose providing opportunities for children during the guided visit to explore and engage with the physical environment in different ways. For instance, participative 
activities could allow them to contextualize physical aspects of the shelter with certain learning contents. In this regard, our results showed that children were able to grasp social values related to empathy, respect, safety and sense of cooperative work. However, the guided visit failed to transmit underlying values and interpretations that could help the students to understand abstract topics such as changes in society (the social role of women during the war and today), different standpoints upon historical events (passive vs. active defense) and long-term effects of the civil war (e.g. collective trauma). The visualization of multiple location-based events allows presenting content from different perspectives and comparing them, e.g. observing civilians from different parts of the city during a bomb alarm; linking the Spanish Civil War to contemporary topics such as the problematic of refugees from Syria, etc. These activities could help children to understand the aforementioned concepts that currently are not fostered through the guided visit alone.

Conceptual changes of children's understanding in relation to these topics could also be achieved through social-aware AR activities. Participative activities based on social interaction have shown to promote mutual reflections between users (Roberts et al., 2014). Thus, we envisioned to implement activities based on using projections of multiple content fragments and a common task (e.g. two children project one piece each of a larger image that together represents a stretcher. They have to move their images in a synchronized way to bring an injured person safely to the infirmary). We argue that by performing and embodying similar actions (Antle et al., 2013; Flynn, 2013; Lyons et al., 2012) to those performed by civilians during the war that these activities could help children to better understand feelings of solidarity and empathy with people in these situations.

\subsection{Exploration of a first prototype based on the WaS paradigm}

Building on the aforementioned results, we defined seven activities based on the use of two Philips PicoPix PPX3414 pico-projectors (figure 7). The system allowed the children to carry around the device and project audiovisual contents directly on the physical environment. In this study, we focused on exploring how projective AR and participative activities that promoted social interaction could enhance the educational experience. The recognition system of surfaces and specific user interaction was still not implemented in this design iteration. Therefore, by pressing a button, the children could switch between and display different audiovisual contents that were uploaded onto the digital library of the projector. The content was organized in a chronological order and the guide indicated when it should be projected. 


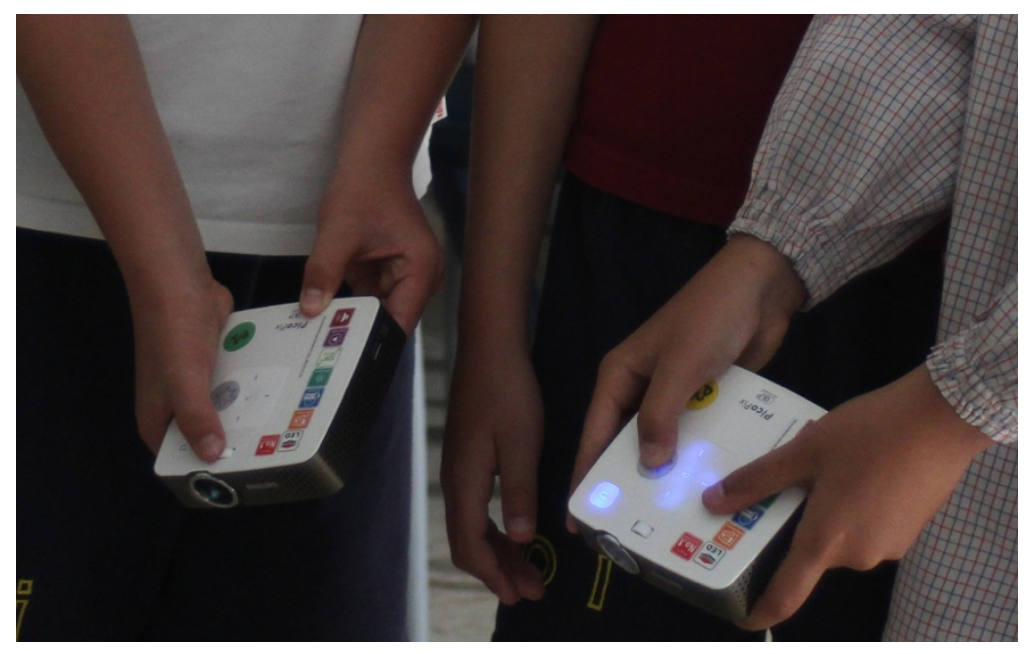

Figure 7: The children holding two Philips PicoPix PPX3414 pico-projectors. The system allowed them to ubiquitously (2) augment the physical space with digital content and (2) perform collaborative activities.

\subsubsection{Procedure}

Six month later after the design workshops, a user study with a preliminary prototype was carried out. A few days before the study, we met with the guide in the shelter to test the WaS system a last time and discussed the procedure of the visit using the prototype. The guide selected the locations in which the digital content would be displayed during the visit. Due to time restrictions, she decided to reduce the original content of the visit and focus on the locations in which we would use the WaS prototype. A total of 20 children (girls $=11$; boys $=9$; age mean $=9.95$ years) participated in the study. The guided visit lasted for 90 minutes. We carried out seven activities based on the WaS system (Table 3 ) to complement the educational experience. Two researchers were present during the visit, video recorded and took notes about children's behaviour and interactions with the prototype. We interviewed the guide about her impressions and reflections upon the activities with the mid-fidelity prototype after the visit. A couple of days later, we conducted a workshop session in school that lasted for 30 minutes to evaluate children's retrospective experience with the prototype. Two researchers facilitated the activities and the session was video recorded.

Table 3: Overview of the seven activities using the prototype during the guided visit

\begin{tabular}{|l|l|}
\hline Activity 1: Entrance & $\begin{array}{l}\text { The guide pointed at the floor with the projector and an animation of an air raid } \\
\text { on the city of Barcelona was reproduced. }\end{array}$ \\
\hline Activity 2: Benches & $\begin{array}{l}\text { One child pointed towards the wall. A video was reproduced where the group } \\
\text { could see people waiting inside a metro station and hear the sound of bombs } \\
\text { exploding in the background. }\end{array}$ \\
\hline $\begin{array}{l}\text { Activity 3: Behavior rule } \\
\text { signs }\end{array}$ & $\begin{array}{l}\text { One child pointed at a stain on the wall and a picture of an old sign containing } \\
\text { the rules of the shelter was displayed. The guide asked the children to read } \\
\text { out aloud the content of the sign. }\end{array}$ \\
\hline $\begin{array}{l}\text { Activity 4: Power } \\
\text { Generator }\end{array}$ & $\begin{array}{l}\text { Two children projected onto two different parts of the original location of the } \\
\text { generator: (1) a switch on the wall and (2) the power source on the ground. }\end{array}$ \\
\hline Activity 5: Infirmary & $\begin{array}{l}\text { Each of two children projected a part of an image representing a stretcher. } \\
\text { They were asked to synchronize their movements and to bring a virtual person } \\
\text { on the projected stretcher safely into the infirmary. }\end{array}$ \\
\hline
\end{tabular}




\begin{tabular}{|l|l|}
\hline $\begin{array}{l}\text { Activity 6: Construction } \\
\text { of shelter }\end{array}$ & $\begin{array}{l}\text { One child projected an image of a group of children helping with the } \\
\text { constructions of the shelter. }\end{array}$ \\
\hline $\begin{array}{l}\text { Activity 7: Comparing } \\
\text { children's drawings } \\
\text { about war }\end{array}$ & $\begin{array}{l}\text { Two children compared two different images. One child pointed at the wall with } \\
\text { the projector and a children's drawing from the late 30s was displayed. Another } \\
\text { child projected a children's drawing from Syria next to the first one. }\end{array}$ \\
\hline
\end{tabular}

Retrospective evaluation of the experience

We started the workshop with a drawing activity. Therefore, the children were asked to draw themselves in the shelter using the projector (performer role) or, if they did not use it, in the role of the "observer" of the interactive experience. After that, the researchers went around with cameras and recorded a short interview with each child. The children explained briefly what they had drawn and why they had chosen this particular representation of themselves and the situation. The aim of the activity was to elicit children's feedback on the educational experience and on using the prototype (Nicol and Hornecker, 2012). The drawings also facilitated to prompt group discussions about the user experience. Therefore, we divided the children into groups of 3-4 members. They were asked to collaboratively reflect upon the educational experience and use of the prototype based on the drawing they had produced. The children wrote their reflections down on post-it notes. The researchers went again around with cameras and recorded a short interview with each group. The aim of the activity was to understand children's perceptions of the user experience. At the same time, the procedure allowed children to compare their attitudes and interpretations with those of other peers and to extend their own reflections.

\subsubsection{Analysis}

In this part of the study, the analysis focused on researching the personal space and the collective space of the experience. For this analysis, we summarized our findings in subcategories, namely (1) educational experience (2) user experience and (3) interaction with the prototype. The physical space and narrative space layer were not relevant for this design stage because they represented requirements of the guided visit which we did not aimed to influence. Our main goal was only to complement the existing educational experience by not altering the physical space and predefined learning contents.

\subsubsection{Results}

\section{Educational experience}

Using digital augmentations in the shelter proved to enhance children's understanding of the historical context in several aspects. In general, the children stated that the projected pictures helped them to imagine certain artefacts and situations in the past. One child said "It was like travelling in time." Another child particularly appreciated that content was displayed in its original locations, for instance the rule signs or the power generator. Two children explained how the activity about the children's drawings had particularly impacted them (figure 8). One boy said: "It is not normal that a six-year-old child draws something like that." Another child explained: "I drew this because it made me sad that a child drew something like that and had to go through this in his country. The child was from Syria." 
Other interpretations were evoked by children's situatedness in the shelter. During the guided visit, children expressed fear when the light was turned off. Several children complained about the cold. They also mentioned that they were afraid of getting lost in the tunnel and they doubted that they would find the exit.

Furthermore, the results indicated that activities based on embodied exploration triggered children's reflections upon underlying values in relation to the historical context. For instance, about the activity in the infirmary, one child in the observer role stated "you needed two carriers for each injured person. If they had to do this for each one who needed help, it was impossible." This finding suggests that observing the enactment of actions from people during the war, helped the child to empathize with the severity of such situations.

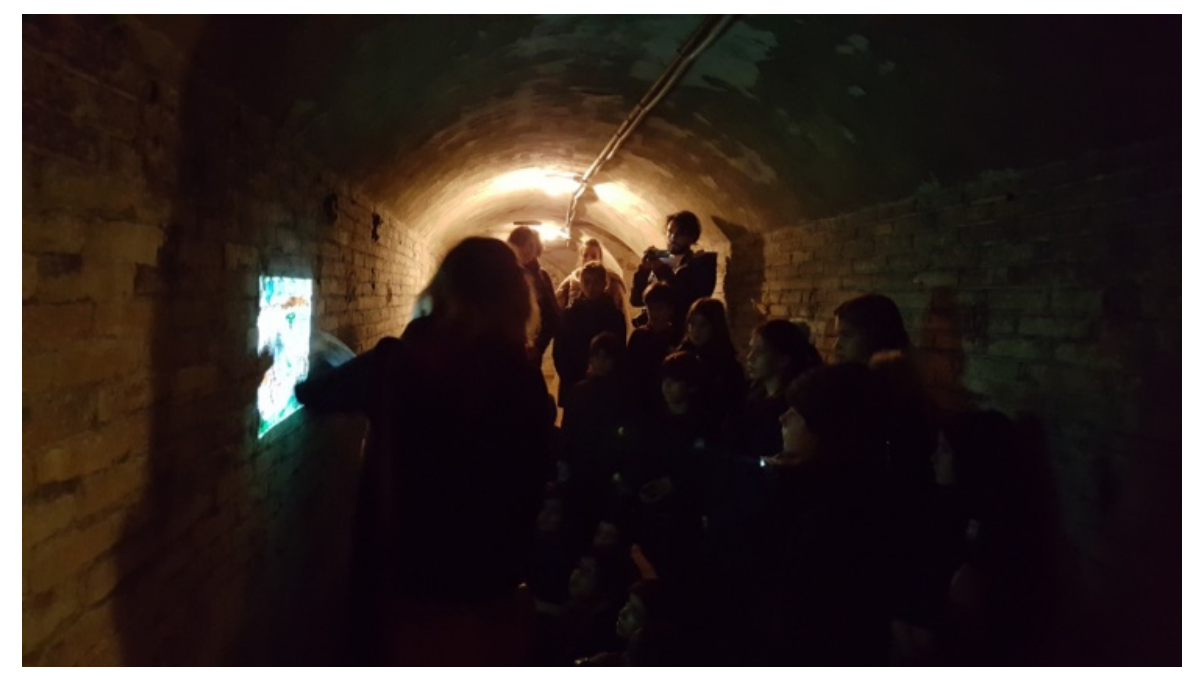

Figure 8: The guide explained the drawing of a child from the war in Syria.

\section{User experience}

Analysing children's drawings and interviews revealed relevant differences between the user experience of (a) the children who held and interacted with the device (performer role: 10 children) and (b) those who observed and interacted with the projection of the prototype (observer role: 10 children). Six children in the observer role represented themselves in a larger group (figure 9, left) during the activity in the "infirmary", "rule signs" and "construction of the shelter". One of these children drew himself facing opposite direction and looking at the children's room. The child also explained during the interview how much he was impacted by this space because it was destroyed during a bomb attack. Three children drew about their experience with a video that showed civilians using a metro station as a shelter. Interestingly, they represented themselves sitting on a bench and another person projecting. One of these children added details to her drawings to depict that the shelter was built into a mountain (figure 9, right). One child represented himself alone. 


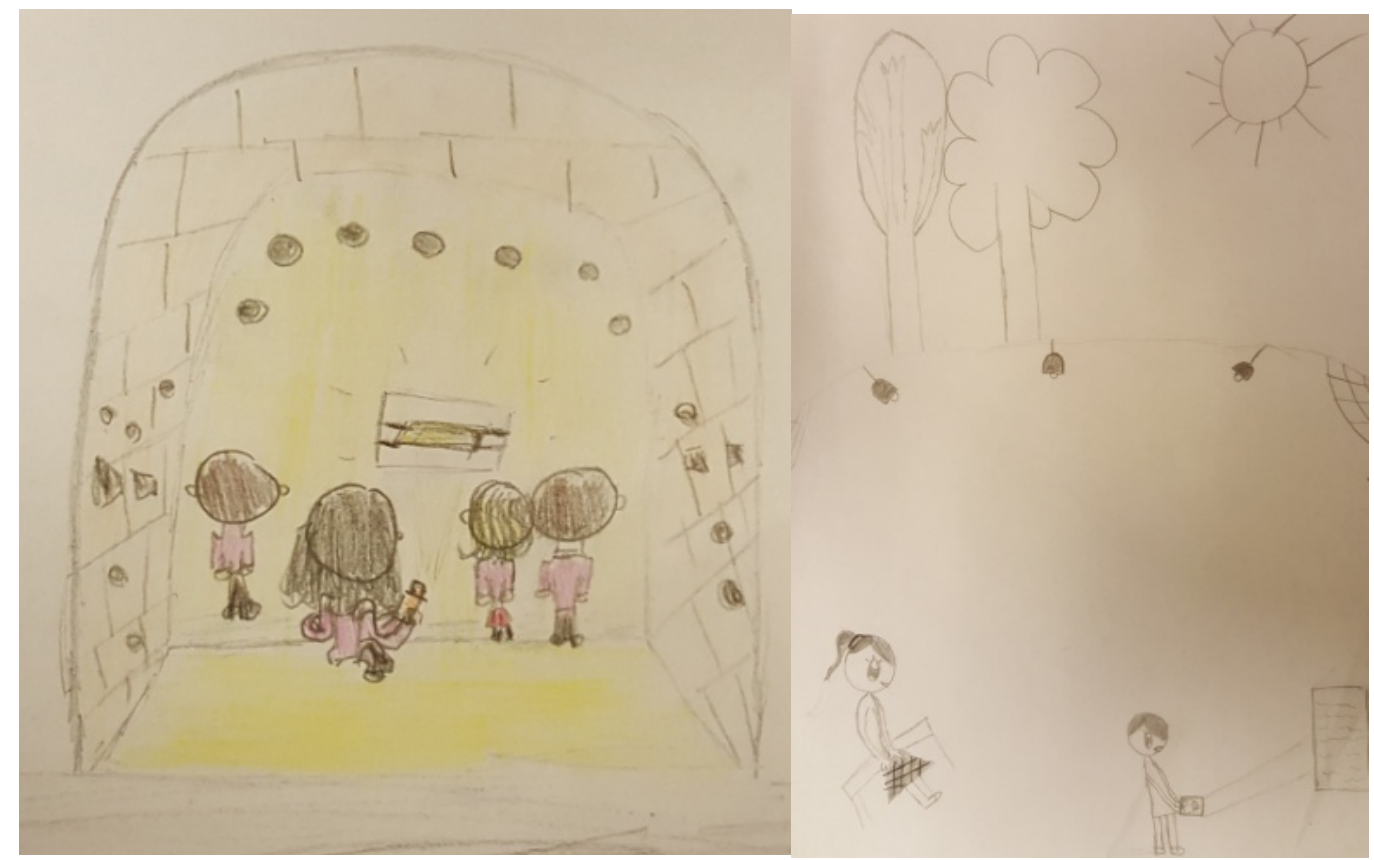

Figure 9: The children in the observer role represented themselves in a group (left) and as passive spectator (right)

In contrast, only one girl in the performer role represented herself in a group. Eight children represented themselves alone and often in the centre of the picture (figure 10). One girl reported during the interview that she was particularly proud to be chosen to use the projector. One boy mentioned that he liked the activity but he could not remember what it was about. Despite having used the projector in a different space, one child focused in her drawing only on the children's room and did not depict any other child. Interestingly, after the visit the guide mentioned that she had perceived that using the projector gives the children a task with a high responsibility. The reason for this perception was probably that they must make sure that the content was well displayed for a certain amount of time. This interpretation was in alignment with the values related "to being a community" that the museum aimed to provide during the visit.

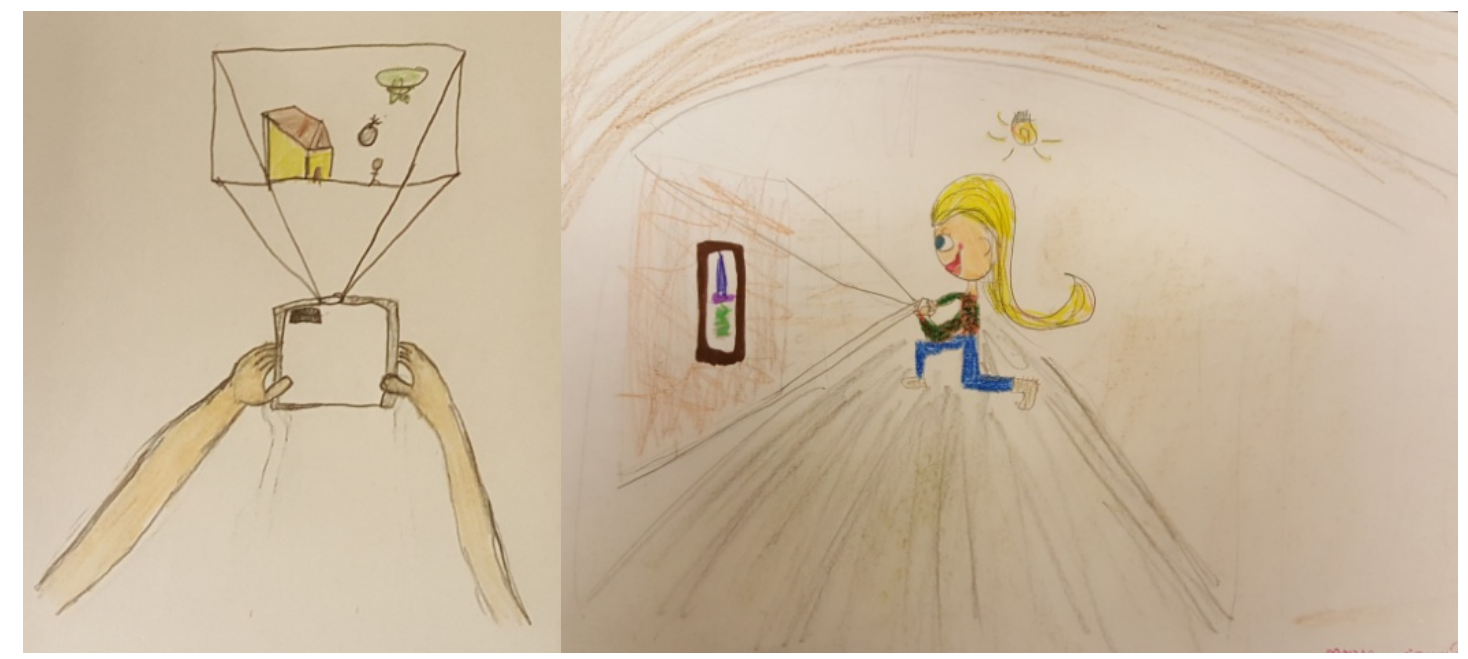


Figure 10: The children in the performer role represented themselves alone and in the centre of the picture.

These findings (figure 11) indicate that activities where the children were forced to remain still and only watch the augmented content was perceived as a passive action and less interesting experience. As a consequence, during these activities the children tended to focus less on the augmented content and explored instead physical features of the shelter with their gaze. Furthermore, we observed a relevant difference between children using the WaS system and those who observed their peers interacting with it. Whereas the children in the observer role mainly lived the activities as a group experience, those who performed the activities using the WaS system were immersed in their task and concentrated on their individual experience. However, the current features of the midfidelity prototype did not allow them to feel part of the collective experience during the activities.

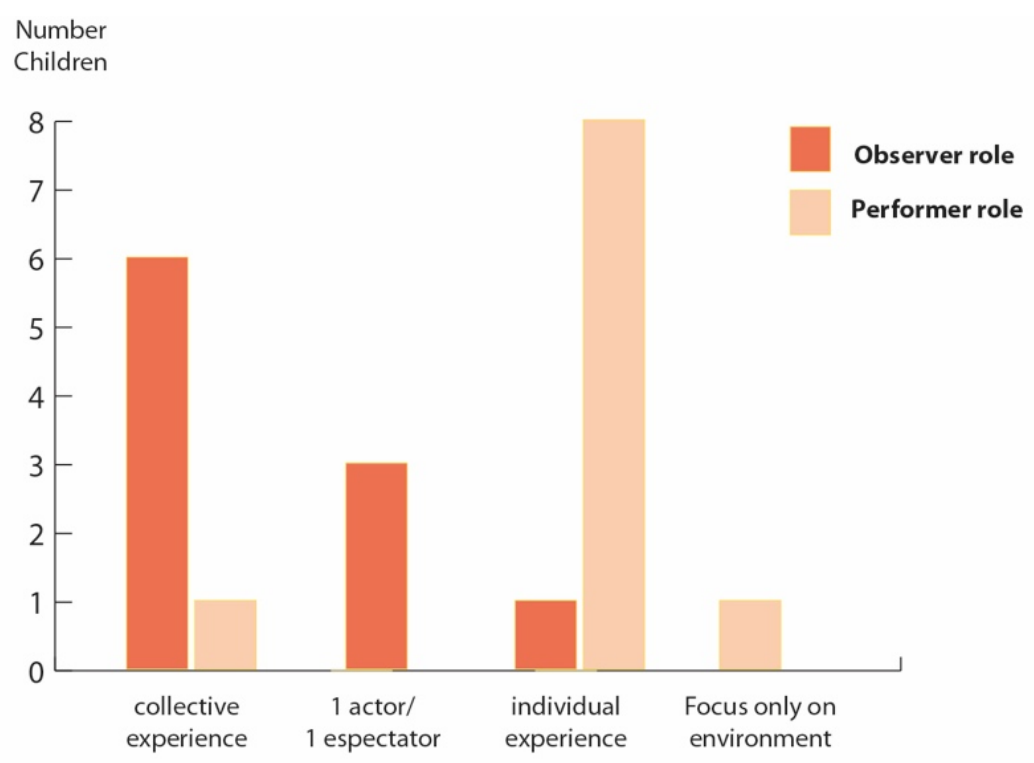

Figure 11: Overview of children's perception of the experience in observer and performer role.

\section{Interaction with the prototype}

Using the prototype in the shelter during the guided visit allowed us to analyze how the children were intuitively interacting with it. We observed several direct interactions with the augmented content. For instance, during the activity at the entrance when a bomb raid was projected, a child cringed when the virtual bomb exploded. Furthermore, one child projected a random image on the head of his peer who started to interact with it. On the other hand, the children tended to point at details in the projection directly with their hands (figure 12, left) or indirectly with their own shadows (figure 12, middle). One child tried to interact with the displayed content by enacting that he would turn off the switch of a power generator (figure 12, right). During the activity in the infirmary, two children immediately understood that the two image parts belonged together. They said "It's like a puzzle." Furthermore, they could easily manage to perform the pre-defined enactment of synchronously moving the stretcher to one part of the space. 

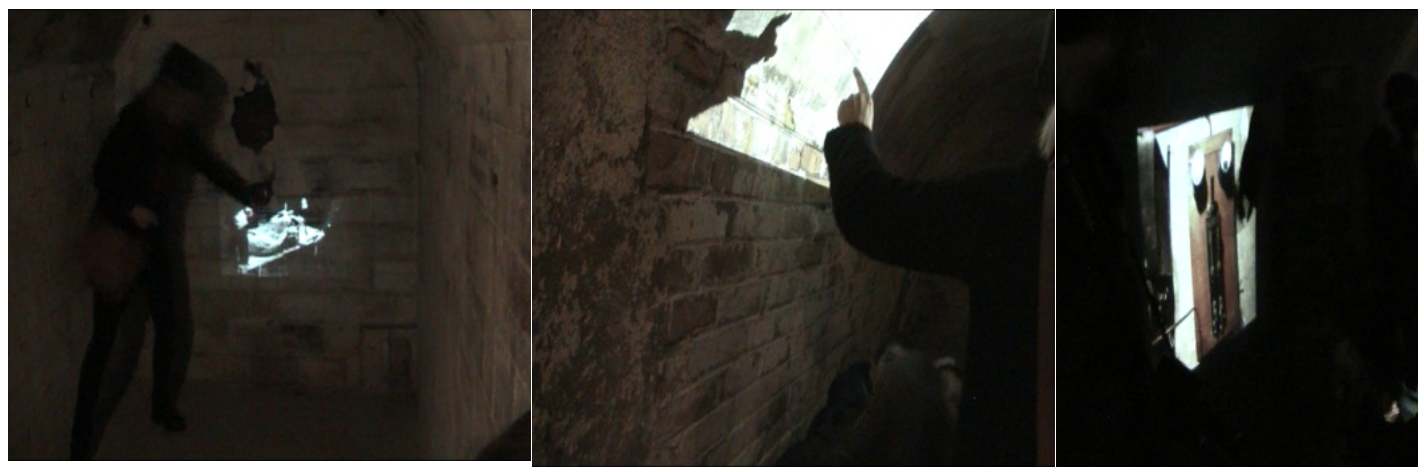

Figure 12: One child interacted directly with the displayed picture (left), one child interacted through his shadow with the displayed picture (middle); one child enacted to switch a power generator on (right)

We observed that the use of videos vs. still pictures triggered different interaction behaviours. Whereas video tended to produce a "cinema effect", i.e. children attentively watched the displayed content, still pictures left room for the interactions previously described. In general, the children enjoyed activities that required an active participation of the entire group. For instance, during one activity, they collectively participated in reading out aloud the rule signs. In this regard, one child mentioned that he liked that he could actively take part in the guided visit instead of only listening to the guide's explanations. At the same time, they liked to investigate and discover different sources, e.g. during the power generated activity.

A general summary of the results is presented in Table 4.

Table 4: Overview of outcomes of the first design iteration

\begin{tabular}{|c|c|}
\hline $\begin{array}{l}\text { Understanding } \\
\text { content }\end{array}$ & $\begin{array}{l}\text { - The displayed content supports children's imagination } \\
\text { - Enactments of people's actions from the past help to empathize } \\
\text { with war related situations } \\
\text { - Comparative tasks stimulate reflection-in action about past events } \\
\text { and contemporary topics } \\
\text { - Situatedness triggers different emotions and helps to foster certain } \\
\text { aspects of the learning content }\end{array}$ \\
\hline User Experience & $\begin{array}{l}\text { - Most activities are perceived by the children in the observer role as } \\
\text { collective experience } \\
\text { Projections that do not promote specific activities cause a "cinema } \\
\text { effect" and are perceived as a passive experience } \\
\text { - Children using the projector perceive themselves as protagonist but } \\
\text { its use prevents an active involvement and being part of the } \\
\text { collective experience }\end{array}$ \\
\hline $\begin{array}{l}\text { Interaction with } \\
\text { Prototype }\end{array}$ & $\begin{array}{l}\text { - Children perform enactments in relation to displayed content } \\
\text { - Children point directly with hands and indirectly through shadows } \\
\text { on the projected content } \\
\text { - } \quad \text { Using two images parts triggers the association with a puzzle game } \\
\text { - Children enact that the displayed images would be interactive and } \\
\text { trigger behaviour changes by certain interactions } \\
\text { - Participative activities stimulate reflection and dialogue }\end{array}$ \\
\hline
\end{tabular}




\section{DISCUSSION}

We have presented the evaluation of a first design iteration of a virtual heritage experience for an archaeological site to explore the potential of an educational experience based on the WaS interaction paradigm for primary school students. Our results indicate benefits to complement the learning experience during the guided visit by (1) supporting activities that involve digital augmentation of the physical space and (2) by encouraging embodied explorations such as spatial interaction, tangible manipulation and the performance of collaborative tasks. We will now discuss these aspects in more detail and outline opportunities for improvements of the prototype.

Digital Augmentation

Employing the WaS system in the shelter allowed the children to visualize missing objects in the physical space and contextualize the guided visit at specific locations through audiovisual material that illustrated certain aspects of historical events. These projections helped children to better understand the learning contents that were difficult to imagine. Furthermore, this feature allowed students to compare different contents at the same time and some preliminary results pointed towards the potential of supporting children's capability in perspective-taking (Ackermann, 1996). However, the museum experts warned on the risk that a too frequent use of the system could limit children's imagination and own reflections (see section 3.1.3, physical space layer). Consequently, the use of projective AR needs to be carefully balanced with other activities aimed to encourage the interpretative construction of meaning.

\section{Embodied Exploration}

In this design iteration, we found evidence that activities involving embodied exploration can enhance children's understanding upon topics requiring emotional engagement (Sakr et al., 2016), critical thinking (Rowan et al., 2016) and the notion of collaboration (Stanton et al., 2001). However, we argue that due to the limited functionality of the current version of the prototype that this feature is still not fully explored. Previous studies (Malinverni and Pares, 2014) have demonstrated that embodied interaction (Dourish, 2001) can support learning of abstract concepts. We envision through an improvement of the functionality of the prototype to foster students' understanding in underlying sociocultural meanings such as the notion of identity (Smith et al., 2011) and solidarity. We believe that particularly activities building on collaborative learning (Doise et al., 1975; Malinverni and Pares, 2015; Nelson, 1994) and a shared construction of meaning (Ackermann, 2004) can promote a better understanding of these concepts. Therefore, we aim to design a system that dynamically recognizes the physical world (i.e. geometry, surfaces, objects and movements) and then projects context-aware digital information directly onto it. This will allow us to take advantage of the benefits of Reality-Based Interaction. These advances will improve the naturalness of the interaction and, consequently, the quality of the user experience which influences the educational experience.

\section{Perception of Agency}

Moreover, we assume that the limitations of the prototype also caused that the children who used the WaS system lived some activities on an individual level or even as a passive experience. Further research is needed to analyse if this shortcoming was caused by the design of certain activities or by the user experience that evoked the features of the system. In this context, it is also important to evaluate how the agency 
between the different users should be distributed. For instance, for some activities, it may be more appropriate that the guide uses the device. Instead, other activities could be guided by children holding the device or, in different contexts, by the group physically interacting with the projected contents.

\subsection{Limitations and future work}

Due to the small sample size of the evaluation study, we argue that the results provide only a snapshot of the ways in which children can benefit from an educational experience based on the WaS interaction paradigm. Further research is needed to confirm our observations and explore the full potential of the WaS system with a more advanced prototype. We are currently developing a second design iteration which is based on a marker-recognition system (Betsworth et al., 2014; Willis et al., 2013). We claim that this approach will allow students to dynamically explore the physical space and increase their context awareness between certain physical aspects and the historical context.

Future work should also explore different formats of the guided visit in combination with the virtual experience. For instance, one variation could be to carry out the guided visit first and then allow children to revisit the shelter using the WaS. This procedure could permit them to explore aspects of the experience motivated by their own interests and leave them more time for discovering new aspects of the learning content at their own pace. However, this has implications on duration of the visit, safety issues and potential liabilities.

Subsequent studies should also widen the evaluation approach of the educational experience and incorporate assessment tools that allow researchers to elicit students' comprehensions and reflections upon abstract concepts such as empathy, identity and solidarity. We also plan to conduct additional project meetings with the experts, to stronger incorporate their viewpoints in the evaluation.

From a broader perspective, we see potential for the WaS system to employ it for general visitors in other application areas such guided tours in indoor and outdoor events, artistic interventions in urban spaces, etc. However, design and assessment tools for these sitespecific experiences cannot be generalized and need to be carefully selected for each context.

\section{Conclusions}

Overall, this paper contributes to the body of advanced interfaces in cultural heritage by presenting and evaluating an educational experience based on the WaS interaction paradigm for primary school children in the context of $\mathrm{CH}$. Our study indicates a first set of benefits of using digital augmentations and participative activities based on embodied exploration. On the one hand, it allowed children to explore the physical environment in meaningful ways and to construct meaning by discovering new layers of the educational experience. On the other hand, the enactment of specific situations allowed the students to more directly experiencing historical content during the visit that required emotional engagement, critical thinking and collaborative learning. In future studies, we will explore further potentials of this approach with an advanced prototype based on a markerrecognition system.

\section{Acknowledgements}


We thank all the children and teachers who have participated with great enthusiasm in our participatory design workshops. We are also very grateful for the support and advice of the management and staff of the History Museum of Barcelona.

Supported by the Spanish Ministry of Economy and Competitiveness (Grant TIN201460599-P).

\section{References}

Ackermann, E.K., 2004. Constructing Knowledge and Transforming the World, A learning zone of one's own: Sharing representations and flow in collaborative learning environments. IOS Press.

Ackermann, E.K., 1996. Perspective-taking and object construction: two keys to learning. Constr. Pract. Des. Thinking, Learn. a Digit. World 25-37.

Antle, A.N., Corness, G., Bevans, A., 2013. Balancing justice: comparing whole body and controller-based interaction for an abstract domain. Int. J. Arts Technol. 6, 388. doi:10.1504/IJART.2013.058285

Bekker, M., Beusmans, J., Keyson, D., Lloyd, P., 2003. KidReporter: A user requirements gathering technique for designing with children. Interact. with Comput. 5438, 7-9. doi:10.1016/S0953-5438(03)00007-9

Betsworth, L., Bowen, H., Robinson, S., Jones, M., 2014. Performative technologies for heritage site regeneration. Pers. Ubiquitous Comput. 18, 1631-1650. doi:10.1007/s00779-014-0766-3

Carreras, A., Parés, N., 2006. Designing an Interactive Installation for Children in a Museum to Learn Abstract Concepts. New Trends Human-Computer Interact. 3342.

Ciolfi, L., McLoughlin, M., 2012. Designing for meaningful visitor engagement at a living history museum, in: Proceedings of the 7th Nordic Conference on HumanComputer Interaction: Making Sense Through Design (NordiCHI '12). ACM, New York, NY, USA, pp. 69-78. doi:10.1145/2399016.2399028

Dindler, C., Iversen, O.S., Smith, R., Veerasawmy, R., 2010. Participatory Design at the Museum: inquiring into children's everyday engagement in cultural heritage, in: In Proceedings of the 22nd Conference of the Computer-Human Interaction Special Interest Group of Australia on Computer-Human Interaction (OZCHI '10). ACM, New York, NY, USA, pp. 72-79. doi:10.1145/1952222.1952239

Doise, W., Mugny, G., Perret-Clermont, A.-N., 1975. Social Interaction and the Development of Cognitive Operations. Eur. J. Soc. Psychol. 5, 367-383. doi:10.1002/ejsp.2420050309

Dourish, P., 2001. Where the Action Is: The Foundations of Embodied Interaction. MIT press. doi:10.1162/leon.2003.36.5.412

Flynn, B., 2013. v-Embodiment for cultural heritage, in: Digital Heritage International Congress. IEEE, Marseille, France, pp. 347-354. doi:10.1109/DigitalHeritage.2013.6743759

Gena, C., De Carolis, B., Kuflik, T., Nunnari, F., 2016. Advanced Visual Interfaces for Cultural Heritage, in: CEUR Workshop Proceedings. pp. 1-4. doi:10.1145/2909132.2927470

Ghali, A., Bayomi, S., Green, J., Pridmore, T., Benford, S., 2003. Vision-mediated interaction with the Nottingham caves, in: Vasudev, B., Hsing, T.R., Tescher, A.G., Ebrahimi, T. (Eds.), Proceedings of the SPIE Conference on Computational Imaging. doi:10.1117/12.476589

Giaccardi, E., Iversen, O.S., 2010. Heritage inquiries: A Designerly Approach to Human Values. Proc. 8th ACM Conf. Des. Interact. Syst. - DIS '10 436. doi:10.1145/1858171.1858258

Green, J., Schnädelbach, H., Koleva, B., Benford, S., Pridmore, T., Medina, K., Harris, 
E., Smith, H., 2002. Camping in the digital wilderness, in: $\mathrm{CHI}$ '02 Extended Abstracts on Human Factors in Computing Systems - CHI '02. ACM Press, New York, New York, USA, p. 780. doi:10.1145/506443.506594

Hornecker, E., Buur, J., 2006. Getting a grip on tangible interaction: a framework on physical space and social interaction., in: Proceedings of the SIGCHI Conference on Human Factors in Computing Systems. ACM, pp. 437-446.

Hornecker, E., Honauer, M., Ciolfi, L., 2014. Technology Augmentation of Historic Cemeteries - A Cross Site Comparison, in: Proceedings of the 8th International Conference on Tangible, Embedded and Embodied Interaction (TEl'14).

Jacob, R.J.K., Girouard, A., Hirshfield, L.M., Horn, M.S., Shaer, O., Solovey, E.T., Zigelbaum, J., 2008. Reality-based interaction: a framework for post-WIMP interfaces., in: Proceedings of the SIGCHI Conference on Human Factors in Computing Systems. ACM, New York, NY, USA, pp. 201-210.

Kenderdine, S., Chan, L.K.Y., Shaw, J., 2014. Pure Land: Futures for Embodied Museography. J. Comput. Cult. Herit. 7, 1-15. doi:10.1145/2614567

Kourakis, S., Aker, C., Pares, N., 2012. We hunters: Interactive communication for young cavemen. Int. J. Arts Technol. 5, 199-220. doi:10.1145/1810543.1810554

Kress, G., 2010. Multimodality. A social semiotic approach to contemporary communication. Routledge, London, UK.

Kynigos, C., Smyrnaiou, Z., Roussou, M., 2010. Exploring rules and underlying concepts while engaged with collaborative full-body games, in: In Proceedings of the 9th International Conference on Interaction Design and Children (IDC '10). ACM, New York, NY, USA, pp. 222-225. doi:10.1145/1810543.1810576

Lanir, J., Wecker, A.J., Kuflik, T., Felberbaum, Y., 2016. Shared mobile displays: an exploratory study of their use in a museum setting. Pers. Ubiquitous Comput. 20, 635-651. doi:10.1007/s00779-016-0931-y

Lentini, L., Decortis, F., 2010. Space and places: When interacting with and in physical space becomes a meaningful experience. Pers. Ubiquitous Comput. 14, 407-415. doi:10.1007/s00779-009-0267-y

Lyons, L., Slattery, B., Jimenez, P., Lopez, B., Moher, T., 2012. Don't forget about the sweat: Effortful embodied interaction in support of learning, in: Proceedings of the Sixth International Conference on Tangible, Embedded and Embodied Interaction (TEI '12). ACM, New York, NY, USA, pp. 77-84. doi:10.1145/2148131.2148149

Malinverni, L., Maya, J., Schaper, M.-M., Pares, N., 2017. The World-as-Support: Embodied Exploration, Understanding and Meaning-Making of the Augmented World, in: Proceedings of the $2017 \mathrm{CHI}$ Conference on Human Factors in Computing Systems (CHI '17). ACM, New York, NY, USA. doi:http://dx.doi.org/10.1145/3025453.3025955

Malinverni, L., Mora-Guiard, J., Pares, N., 2016. Towards Methods for Evaluating and Communicating Participatory Design: a Multimodal Approach. Int. J. Hum. Comput. Stud. Manuscript submitted for publication. doi:10.1016/j.ijhcs.2016.03.004

Malinverni, L., Pares, N., 2015. The Medium Matters: the Impact of Full-Body Interaction on the Socio-Affective Aspects of Collaboration, in: IDC '15 Proceedings of the 2015 Conference on Interaction Design and Children. ACM, New York, NY, USA. doi:10.1145/2771839.2771849

Malinverni, L., Pares, N., 2014. Learning of Abstract Concepts through Embodied Interaction: a 10 years systematic review of Full Body Interaction Learning Environments. J. Educ. Technol. Soc. 17, 100-116.

Marshall, M.T., Dulake, N., Ciolfi, L., Duranti, D., Kockelkorn, H., Petrelli, D., Haag, D., 2016. Using Tangible Smart Replicas as Controls for an Interactive Museum Exhibition. Tangible Embodied Interact. 159-167. doi:10.1145/2839462.2839493

Milgram, P., Kishino, F., 1994. A Taxonomy of Mixed Reality Visual Displays. IEICE Trans. Inf. Syst. 1-15.

Mokatren, M., Kuflik, T., Shimshoni, li., 2016. A Novel Image Based Positioning 
Technique Using Mobile Eye Tracker For A Museum Visit, in: Proceedings of the 18th International Conference on Human-Computer Interaction with Mobile Devices and Services Adjunct (MobileHCl '16). ACM, New York, NY, USA, pp. 984-991.

Müller, J., Rädle, R., Reiterer, H., 2016. Virtual Objects as Spatial Cues in Collaborative Mixed Reality Environments: How They Shape Communication Behavior and User Task Load., in: Proceedings of the $2016 \mathrm{CHI}$ Conference on Human Factors in Computing Systems (CHI '16). ACM, New York, NY, USA, pp. 1245-1249.

Muller, M.J., Druin, A., 2003. Participatory Design : The Third Space in $\mathrm{HCl}$, in: HumanComputer Interaction: Development Process. pp. 1-70.

Nathan, M.J., Robinson, C., 2001. Considerations of Learning and Learning Research: Revisiting the "Media Effects" Debate. J. Interact. Learn. Res. 12(1), 69-88.

Nelson, C.E., 1994. Critical thinking and collaborative learning. New Dir. Teach. Learn. 1994, 45-58. doi:10.1002/tl.37219945907

Nicol, E., Hornecker, E., 2012. Using Children's Drawings to Elicit Feedback on Interactive Museum Prototypes, in: Proceedings of the 11th International Conference on Interaction Design and Children (IDC'12). ACM, New York, NY, USA, pp. 276-279. doi:10.1145/2307096.2307144

Pacheco, D., Wierenga, S., Omedas, P., Oliva, L.S., Wilbricht, S., Billib, S., Knoch, H., Verschure, P., ., 2015. A location-based Augmented Reality system for the spatial interaction with historical datasets. Digit. Herit. 1, 393-396. doi:10.13140/RG.2.1.3957.4487

Petrelli, D., Ciolfi, L., Dijk, D. Van, Hornecker, E., Not, E., 2013. Integrating Material and Digital: A New Way for Cultural Heritage. ACM Interact. 20, 58-63.

Pietroni, E., Adami, A., 2014. Interacting with Virtual Reconstructions in Museums. J. Comput. Cult. Herit. 7, 1-29. doi:10.1145/2611375

Price, S., Jewitt, C., 2013. Interview Approaches to Researching Embodiment 29072910.

Price, S., Sakr, M., Jewitt, C., 2015. Exploring Whole-Body Interaction and Design for Museums. Interacting with Computers. Interact. Comput. 28, 569-583. doi:10.1093/iwc/iwv032

Rennick-Egglestone, S., Roussou, M., Brundell, P., Chaffardon, C., Kourtis, V., Koleva, B., Benford, S., 2013. Indoors and outdoors: designing mobile experiences for Cité de l'espace, in: Proceedings of NODEM. NODEM, Kista, Sweden.

Rowan, L., Townend, G., Beavis, C., Kelly, L., Fletcher, J., 2016. Museums, Games, and Historical Imagination: Student Responses To a Games-Based Experience At the Australian National Maritime Museum. Digit. Educ. Cult. 8, 1-21.

Sakr, M., Jewitt, C., Price, S., 2016. Mobile Experiences of Historical Place: A Multimodal Analysis of Emotional Engagement. J. Learn. Sci. 25, 51-92. doi:10.1080/10508406.2015.1115761

Scaife, M., Rogers, Y., 1999. Kids as Informants: Telling us what we didn ' $t$ know or confirming what we knew already? 1-26.

Schaper, M.-M., Santos, M., Malinverni, L., Pares, N., 2017. Towards the Design of a Virtual Heritage Experience based on the World-as-Support Interaction Paradigm, in: In Proceedings of 35th the $\mathrm{CHI}$ Conference on Human Factors in Computing Systems (CHI'17).

Smith, R., Iversen, O., Dindler, C., 2011. Digital Natives: Creating Emergent Exhibitions through Digital Technologies. Rethink. Technol. Museums Emerg. Exp. 13-25.

Stanton, D., Bayon, V., Neale, H., Ghali, A., Benford, S., Cobb, S., Ingram, R., O'Malley, C., Wilson, J., Pridmore, T., 2001. Classroom collaboration in the design of tangible interfaces for storytelling. SIGCHI Conf. 482-489. doi:10.1145/365024.365322

Stanton, D., O'Malley, C., Huing, K., Fraser, M., Benford, S., 2003. Situating Historical Events Through Mixed Reality, in: Designing for Change in Networked Learning 
Environments. Springer Netherlands, Dordrecht, pp. 293-302. doi:10.1007/97894-017-0195-2_37

Tarumi H.a Yamada, K.. D.T.. K.F.. I.S.. T.M.. H.T.. Y.M.., 2008. KEl-Time Traveler: Visiting a past world with mobile phones to enhance learning motivation, in: Proceedings of the 7th International Conference on Interaction Design and Children, IDC 2008. pp. 161-164. doi:10.1145/1463689.1463746

Van Mechelen, M., Derboven, J., Laenen, A., Willems, B., Geerts, D., Vanden Abeele, V., 2016. The GLID method: Moving from design features to underlying values in co-design. Int. J. Hum. Comput. Stud. 97, 116-128. doi:10.1016/j.ijhcs.2016.09.005

Walsh, G., Foss, E., Yip, J., Druin, A., 2013. FACIT PD: a framework for analysis and creation of intergenerational techniques for participatory design. ... SIGCHI Conf. Hum. ... 2893-2902. doi:10.1145/2470654.2481400

Willis, K.D.D., Shiratori, T., Mahler, M., 2013. HideOut: Mobile Projector Interaction with Tangible Objects and Surfaces b e a c d f, in: Proceedings of the 7th International Conference on Tangible, Embedded and Embodied Interaction (TEI '13). ACM, New York, NY, USA.

Wixon, D., Holtzblatt, K., Knox, S., 1990. Contextual design: an emergent view of system design, in: Proceedings of the SIGCHI Conference on Human Factors in Computing Systems Empowering People - CHI '90. pp. 329-336.

doi:10.1145/97243.97304 